\title{
Review Article \\ Interaction between Walking Humans and Structures in Vertical Direction: A Literature Review
}

\author{
Erfan Shahabpoor, ${ }^{1}$ Aleksandar Pavic, ${ }^{2}$ and Vitomir Racic ${ }^{3,4}$ \\ ${ }^{1}$ INSIGNEO Institute for In Silico Medicine, The University of Sheffield, Department of Civil \& Structural Engineering, \\ Sir Frederick Mappin Building, Mappin Street, Sheffield S1 3JD, UK \\ ${ }^{2}$ College of Engineering, Mathematics and Physical Sciences, Vibration Engineering Section, University of Exeter, \\ North Park Road, Exeter EX4 4QF, UK \\ ${ }^{3}$ Department of Civil and Environmental Engineering, Politecnico di Milano, Piazza di Leonardo Da Vinci 32, 20133 Milan, Italy \\ ${ }^{4}$ Department of Civil \& Structural Engineering, The University of Sheffield, Sir Frederick Mappin Building, Mappin Street, \\ Sheffield S1 3JD, UK \\ Correspondence should be addressed to Erfan Shahabpoor; e.shahabpoor@sheffield.ac.uk
}

Received 19 March 2016; Accepted 27 April 2016

Academic Editor: Tai Thai

Copyright (C) 2016 Erfan Shahabpoor et al. This is an open access article distributed under the Creative Commons Attribution License, which permits unrestricted use, distribution, and reproduction in any medium, provided the original work is properly cited.

Realistic simulation of the dynamic effects of walking pedestrians on structures is still a considerable challenge. This is mainly due to the inter- and intrasubject variability of humans and their bodies and difficult-to-predict loading scenarios, including multipedestrian walking traffic and unknown human-structure interaction (HSI) mechanisms. Over the past three decades, several attempts have been made to simulate walking HSI in the lateral direction. However, research into the mechanisms of this interaction in the vertical direction, despite its higher likelihood and critical importance, is fragmented and incoherent. It is, therefore, difficult to apply and codify. This paper critically reviews the efforts to date to simulate walking HSI in the vertical direction and highlights the key areas that need further investigation.

\section{Introduction}

The vibration serviceability of many modern structures, such as footbridges, stadia, and long-span floors under human loading, increasingly governs their design and determines their cost. Inadequate consideration of the effects of walking pedestrians on structural performance can lead to a considerable financial loss, such as in the case of the infamous London Millennium Bridge in 2000 [1, 2]. It is particularly an issue today, with high aesthetic demands and new lightweight materials of increasing strength affecting the vibration serviceability performance.

Regardless of its importance, recurring incidences of vibration serviceability failures due to walking pedestrians, in both the vertical and horizontal directions, have highlighted the inability of current design methods to reliably estimate the structural response $[3,4]$. This unreliable performance is primarily due to virtually all design methods ignoring the human-structure interaction (HSI) and sometimes dismissing the natural inter- and intrasubject variability of people [4-8]. The excessive lateral vibration of the Paris Solferino Bridge and the London Millennium Bridge on their opening days triggered a wave of research on HSI in the lateral direction after 2000 [9]. However, the interaction of walking people with structures in the vertical direction, despite being much more frequent and relevant to everyday design practice, has sparsely been explored.

HSI was initially considered to be nonexistent for moving humans [10]. However, it was subsequently demonstrated that it could have significant effects on the structural response [11]. Recently, a more realistic estimation of the structural vibration response was made possible by taking into account the inter- and intrasubject variability of the pedestrians in the form of statistical models of their walking force $[6,12-$ 17]. This has considerably increased the fidelity of the walking force models, but they still struggle to capture key features of human-structure interaction (HSI) $[4,8]$. The main reason 
is the lack of credible experimental data to understand and model HSI.

In the context of the vibration serviceability of structures, HSI is defined here as the continuous mutual dynamic effects of a human and structure on each other that acts in a feedback loop as long as the structure and human on it are in contact. HSI is dependent on the human body posture and the type of activity [18] and can affect structural response through different mechanisms and in different directions. Based on the classification proposed by Sachse [19] and assuming the human body as a mass-spring-damper (MSD) system, HSI mechanisms can be divided into two categories. The first category comprises the effects of the human body (perceived as a dynamic system) on the dynamic properties of the structure, namely, mass, stiffness, and damping. The second category comprises the effects of the structural vibrations on the forces induced by human occupants. For walking people, this includes effects of the structural vibration on the gait parameters, such as the pacing frequency and phase, stride length, and walking speed.

This paper focuses on the interaction of the walking people with structures in the vertical direction. The influence pedestrians have on each other's walking patterns is not considered to be HSI in this study. Therefore, cases where the synchronisation of people is significant within a spatially restricted crowd due to a prompt $[20,21]$ that can be provided by music, movements of other people [22, 23], or visual and audio contact between people [19] are not discussed here.

The two categories of the vertical HSI mentioned above are discussed in more detail in Sections 2 and 3 of this paper. Section 2.1 reviews the experimental evidence in the literature on the effects of walking humans on the modal properties of the structure. Various proposed walking human models that take the HSI into account are discussed in Section 2.2. Section 3 examines the effects of the structural vibrations on the human walking parameters, including the "lock-in" effect in the vertical direction. The approach of the current design guidelines to taking HSI into account is discussed in Section 4 and conclusions are presented in Section 5.

\section{Effects of a Walking Human on the Modal Properties of a Structure}

As previously mentioned, one of the key mechanisms of the HSI in the vertical direction is the potential of the human body to change the dynamic properties of the structure (mass $m$, damping $c$, and stiffness $k$ ) over which it moves. It is well known that the mass of a stationary human body accelerates when exposed to structural vibration and applies interaction force on the structure [24]. The same principle applies to the moving body, in which case a ground reaction force (GRF) is created due to the base vibration. This GRF in addition to the GRF is caused by the internal propulsion of the body locomotor system during walking on a stiff surface and manifests itself as changes in the modal frequency (i.e., mass and/or stiffness) and damping of the empty structure. This is because such GRF has components proportional to the acceleration, velocity, and displacement of the structure, as well as independent components [25].
Several studies in the past have noted the increase of damping and/or changes of the natural frequencies of structures when they are occupied by stationary (standing or sitting) people [26-30]. However, studies are rare concerning changes in dynamic properties of the structure due to moving (e.g., walking and running) people in the vertical direction $[11,31,32]$.

2.1. Experimental Evidences. Ohlsson [33] reported that the spectrum of a walking force measured on a rigid surface was different from that measured on a flexible timber floor. The spectrum showed a drop around the natural frequency of the structure where the response was prominent. He also observed that a moving pedestrian increased both the mass and the damping of the structure. Baumann and Bachmann [34] similarly reported dynamic load factors (DLFs) of walking, which were up to $10 \%$ lower if measured on a flexible $19 \mathrm{~m}$ long prestressed beam. These observations were confirmed by Pimentel [35], who reported lower DLFs on moving footbridges compared to those measured on a rigid surfaces. $\mathrm{He}$ also reported a reduction in the natural frequency of a test footbridge under a walking human load.

The measurements of Ebrahimpour et al. [36] on a purpose-built instrumented platform showed that the damping and mass of the platform were dependent on the number of walking people on it. In a different set of experiments on the same test structure, Ebrahimpour and Sack [37] found that walking DLFs decreased as the number of walking people increased. The investigations of Bishop et al. [38] and Pimentel and Waldron [39] also showed that moving human occupants add damping to structures they occupy. A similar trend was observed for standing people shortly afterwards by Ellis and Ji [10] and Sachse et al. [26]. However, studies of Ellis and Ji [10] did not show any considerable effects of jumping and walking people on the modal properties of structures.

In 2002, Willford [2] described experiments on the Millennium Bridge and reported an increase in the damping of the footbridge under walking load in the vertical direction. Later, in 2004, Brownjohn et al. [40] reported results of a combination of forced vibration testing and human forcing on a 1,300-tonne footbridge in Singapore. The footbridge was a steel skeleton, clad with glass, spanning $140 \mathrm{~m}$ between pin supports, at the platform level of a rapid transit railway terminus. During some of the tests, 150 pedestrians were walking on the footbridge for several minutes. The results of their analysis in the vertical direction showed an increase in the level of damping. The values of the damping recorded were found to lie in between that of an empty footbridge and that of a footbridge full of stationary pedestrians.

The studies of Brownjohn and $\mathrm{Fu}$ [41] on a $46 \mathrm{~m}$ steel footbridge linking a teaching block and an engineering block at Singapore Polytechnic showed that the changes in the modal properties of the structure with moving pedestrians were small compared to those with stationary pedestrians. They suggest that, within limits, the modal properties of the empty structure could be used in analysis.

Živanović et al. [11] carried out a systematic set of experiments on a full-scale pedestrian structure to quantify the effects of walking and standing people on the modal 


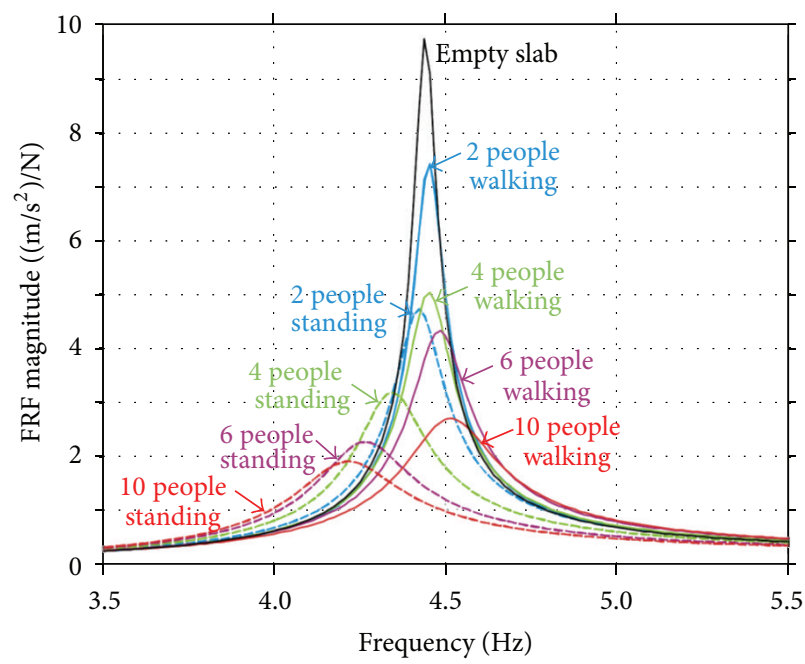

(a)

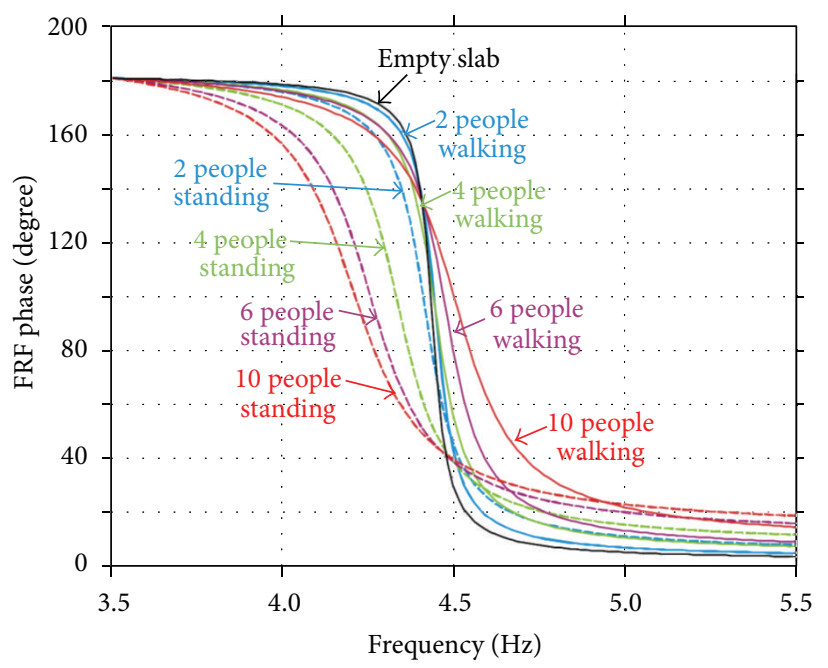

(b)

FIGURE 1: FRF magnitude and phase graphs of Sheffield University test footbridge understanding/walking groups of people [11].

properties of the structure. Groups of 2, 4, 6, and 10 people were asked to stand still or walk along the Sheffield University posttensioned simply supported slab footbridge. For each loading scenario, an FRF-based modal test was carried out using an APS electrodynamic shaker connected directly to the midspan of the structure to excite the first mode. The experimentally measured FRFs of the occupied structure under different loading scenarios (Figure 1) were curve-fitted to find the modal properties of the occupied structure. It was found that the presence of humans on the structure, either in passive or in active form, increased its damping. Interestingly, it was also found that the presence of standing people increased the natural frequency of the structure, while the same people walking decreased it.

Živanović et al. [4] conducted an extensive set of vibration monitoring tests on Podgorica footbridge in Montenegro under a daily walking pedestrian load. Their study showed a threefold increase in the effective damping of the first-vertical mode of the structure from $0.26 \%$ to $0.67 \%$. Similarly, the experimental and analytical studies of Fanning et al. [42] on the vibration serviceability of Sean O'Casey Bridge in Dublin showed that the measured acceleration response of the structure was $20 \%$ less than the corresponding analytical value. They concluded that this was due to the added damping of the walking people on the structure.

Dong et al. [43] performed a series of tests on the Olga footbridge at Oberhausen, Germany, under a stream of walking pedestrians. The bridge had the total length of $66 \mathrm{~m}$, with two spans of $18 \mathrm{~m}$ and $48 \mathrm{~m}$. First, the vertical mode of vibration, with a natural frequency of $1.8 \mathrm{~Hz}$ and damping ratio of $0.5 \%$, was found to be the most sensitive to the walking pedestrian effects. It was found that, during the highest arrival rate period, the natural frequency reduced to $1.72 \mathrm{~Hz}$ and the damping ratio increased to $1.9 \%$.

Georgakis and Jorgensen [32] did a series of forced vibration tests on a purposefully built test footbridge to quantify the effects of walking pedestrians on the mass and damping of the structure. The footbridge was a simply supported $16 \mathrm{~m}$ long double U-beam steel structure with the mass of $5,224 \mathrm{~kg}$, natural frequency of $2.23 \mathrm{~Hz}$, and amplitude-dependent damping of $0.25-0.58 \%$. Three tests were carried out, each lasting a minimum of 3 minutes. In these tests, 4,7 , and 10 pedestrians, representing $0.35,0.62$, and 0.88 pedestrians/s flow rates, respectively, walked on the structure. The results of the analysis showed that the full mass of a human body (and not a fraction of it) can be used to simulate a single pedestrian. They also found that the Weibull distribution can describe the probability distribution of the observed added damping values for each pedestrian. An exponential fit was then made to the data to find amplitude-dependent and flow-independent pedestrian damping coefficients, $c_{p}$, for varying probability (fractile) levels (Figure 2). They finally suggested that, for design purposes, a pedestrian may be treated as a moving point viscous damper with $c_{p}=500 \mathrm{~N} \cdot \mathrm{s} / \mathrm{m}$ for moderate vertical vibrations of up to $5 \mathrm{~mm}$ amplitude.

As recently as 2015, Zhang et al. [44], Van Nimmen et al. [45], and Salyards and Hua [46] carried out a set of experiments on full-scale structures and reported a considerable increase in the damping ratio and a slight change in the natural frequency of the structure occupied by walking people or stationary people with bent knees.

Shahabpoor et al. [50,51] carried out a set of FRF-based modal tests on a test structure with groups of 3-15 people walking on it. The analysis considered the first two modes of the structural vibration, with natural frequencies of $4.44 \mathrm{~Hz}$ and $16.8 \mathrm{~Hz}$ and modal damping ratios of $0.7 \%$ and $0.4 \%$, respectively, with a modal mass of $7128 \mathrm{~kg}$ for both modes. Pedestrians were asked to walk at their desired speed on the structure. A considerable change in the modal parameters of the structure was reported when it was occupied by walking people (Table 1). For example, for a group of 10 people walking at midspan, an increase of natural frequency to $4.75 \mathrm{~Hz}$, modal mass to $7311 \mathrm{~kg}$, and modal damping ratio 
TABLE 1: Modal properties of the occupied structure (os) for different group sizes.

\begin{tabular}{|c|c|c|c|c|c|c|c|c|c|c|}
\hline \multirow{2}{*}{ Test number } & \multirow{2}{*}{ Series } & \multirow{2}{*}{ Location } & \multirow{2}{*}{ Number of pedestrians } & \multicolumn{5}{|c|}{ Modal properties of the occupied structure (os) } & \multicolumn{2}{|c|}{ Structural response } \\
\hline & & & & $f_{\mathrm{os}}(\mathrm{Hz})$ & $\zeta_{\mathrm{os}}(\%)$ & $m_{\mathrm{os}}(\mathrm{kg})$ & $c_{\mathrm{os}}(\mathrm{N} \cdot \mathrm{s} / \mathrm{m})$ & $k_{\mathrm{os}}(\mathrm{N} / \mathrm{m})$ & $a_{\max }\left(\mathrm{m} / \mathrm{s}^{2}\right)$ & $a_{\mathrm{rms}}\left(\mathrm{m} / \mathrm{s}^{2}\right)$ \\
\hline \multicolumn{11}{|c|}{ Mode 1 (structure) } \\
\hline 1.1 & A & All-over & 2 & 4.443 & 1.00 & 7,165 & 4,000 & $5,583 \times 10^{3}$ & 2.4361 & 0.4131 \\
\hline 1.2 & $\mathrm{~B}$ & All-over & 3 & 4.445 & 1.10 & 7,183 & 4,413 & $5,603 \times 10^{3}$ & 1.7489 & 0.3018 \\
\hline 1.3 & $\mathrm{~A}$ & All-over & 4 & 4.450 & 1.28 & 7,201 & 5,154 & $5,630 \times 10^{3}$ & 2.1755 & 0.3637 \\
\hline 1.4 & $\mathrm{~A}$ & All-over & 6 & 4.465 & 1.55 & 7,238 & 6,294 & $5,696 \times 10^{3}$ & 1.8771 & 0.3311 \\
\hline 1.5 & B & All-over & 6 & 4.465 & 1.65 & 7,238 & 6,701 & $5,696 \times 10^{3}$ & 1.4882 & 0.2481 \\
\hline 1.6 & B & All-over & 10 & 4.475 & 2.30 & 7,311 & 9,456 & $5,780 \times 10^{3}$ & 1.1313 & 0.2050 \\
\hline 1.7 & $\mathrm{~A}$ & All-over & 10 & 4.476 & 2.10 & 7,311 & 8,635 & $5,782 \times 10^{3}$ & 1.5876 & 0.2870 \\
\hline 1.8 & A & All-over & 15 & 4.485 & 2.91 & 7,402 & 12,140 & $5,878 \times 10^{3}$ & 1.1251 & 0.2466 \\
\hline \multicolumn{11}{|c|}{ Mode 2 (structure) } \\
\hline 2.1 & B & All-over & 3 & 16.900 & 0.55 & 7,128 & 8,326 & $80,372 \times 10^{3}$ & 2.4059 & 0.4482 \\
\hline 2.2 & $\mathrm{~A}$ & All-over & 6 & 16.813 & 0.53 & 7,128 & 7,982 & $79,548 \times 10^{3}$ & 2.9046 & 0.5595 \\
\hline 2.3 & B & All-over & 6 & 16.910 & 0.65 & 7,128 & 9,846 & $80,468 \times 10^{3}$ & 2.2905 & 0.4234 \\
\hline 2.4 & $\mathrm{~A}$ & All-over & 8 & 16.819 & 0.61 & 7,128 & 9,190 & $79,605 \times 10^{3}$ & 2.5591 & 0.5133 \\
\hline 2.5 & $\mathrm{~A}$ & All-over & 10 & 16.822 & 0.64 & 7,128 & 9,644 & $79,634 \times 10^{3}$ & 2.5232 & 0.5223 \\
\hline 2.6 & B & All-over & 10 & 16.935 & 0.75 & 7,128 & 11,377 & $80,708 \times 10^{3}$ & 2.1387 & 0.4023 \\
\hline 2.7 & $\mathrm{~A}$ & All-over & 15 & 16.825 & 0.79 & 7,128 & 11,907 & $79,665 \times 10^{3}$ & 2.2358 & 0.4725 \\
\hline
\end{tabular}

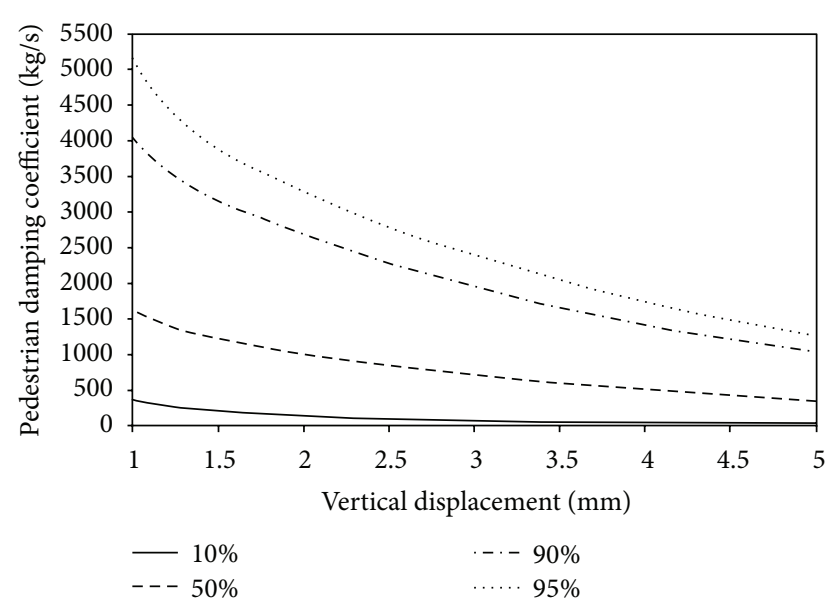

FIGURE 2: Amplitude-dependent pedestrian damping coefficient for varying probability fractile [32].

to $2.3 \%$ was observed. In addition, the magnitude of the interaction effects was found directly related to the number of walking people on the structure.

The aforementioned experimentally measured effects of the walking human-structure interaction on the modal properties of structures are summarised in Table 2, where arrows pointing upwards/downwards indicate the observed increase/decrease in the corresponding modal property during walking. Apart from the Ellis and Ji [10] study, all other measurements show an increased structural damping ratio $\zeta_{s}$ due to the presence of walking people, compared to damping ratio of an empty structure. The measurement of the modal frequencies of the structures $f_{s}$ shows both an increase and a decrease in $f_{s}$ due to walking humans. The trend of change of $f_{s}$ is consistent with the theoretical explanation offered by Shahabpoor et al. [52]. Using a two-degree-of-freedom human-structure model, they found that when the natural frequency of the human model $f_{h}$ is less than that of the empty structure $f_{s}$, the natural frequency of the occupied structure $f_{\text {os }}$ is higher than $f_{s}$. On the other hand, when $f_{h}$ is more than $f_{s}, f_{\text {os }}$ is less than $f_{s}$. A detailed description of their findings is presented in Section 2.2.1.

2.2. Walking Human Models. Assuming a walking human to be a linear mechanical system makes it possible to use the superposition principle to split the walking GRF on a vibrating structure into two components:

(1) The walking GRF on a stiff surface resulting solely from the internal propulsion of the locomotor system.

(2) The interaction force resulting from the acceleration of body masses due to structural vibrations.

The models that use this analogy usually have two components. The first component is comprised of a walking GRF corresponding to a stiff surface (called noninteractive $G R F$ here). This force is either synthetically generated or experimentally measured, typically using an instrumented treadmill. The second component is usually a physical human model, which simulates the interaction effects. Both forces are usually applied independently on the structure and their location sometimes changes as the human walks along a structure. The HSI physical models (second component) proposed in the literature are discussed in this section.

It is worth mentioning that, in almost all the cases, the physical walking human models are only focused on simulating the first category of HSI effects, that is, the effects of the human body on the dynamic properties of the structure. The second category of HSI effects (the effects of the structural vibrations on human occupants), however, is 
TABLE 2: Experimentally measured effects of HSI on modal properties of structure.

\begin{tabular}{|c|c|c|c|c|c|c|}
\hline Study & Number of pedestrians & Structure & $\zeta_{s}$ & $f_{s}$ & $a_{s}$ & DLFs \\
\hline Ohlsson, 1982 [33] & - & Timber floor & $\uparrow$ & $\downarrow$ & $\downarrow$ & - \\
\hline $\begin{array}{l}\text { Baumann and } \\
\text { Bachmann, } 1988 \text { [34] }\end{array}$ & - & $19 \mathrm{~m}$ prestressed beam & - & - & - & $10 \% \downarrow$ \\
\hline $\begin{array}{l}\text { Ebrahimpour et al., } 1989 \\
\text { [36] }\end{array}$ & $1-40$ & Lab-based composite floor & $\uparrow$ & - & $\downarrow$ & - \\
\hline $\begin{array}{l}\text { Ebrahimpour and Sack, } \\
1996 \text { [37] }\end{array}$ & $1-40$ & Lab-based composite floor & - & - & - & $\downarrow$ \\
\hline $\begin{array}{l}\text { Pimentel and Waldron, } \\
1996 \text { [39] }\end{array}$ & 1 & $\begin{array}{l}\text { Composite footbridge } \\
f=3.66 \mathrm{~Hz}, \zeta=0.4 \%\end{array}$ & $\uparrow$ & - & - & $\downarrow$ \\
\hline Ellis and Ji, 1997 [10] & 1 & $\begin{array}{l}\text { Precast reinforced concrete beam } \\
\quad f=18.68 \mathrm{~Hz}, \zeta=0.8 \%\end{array}$ & $0 \%$ & $0 \%$ & - & - \\
\hline Pimentel, 1997 [35] & - & $\begin{array}{c}\text { Stressed ribbon footbridge } \\
f=2.35 \mathrm{~Hz}, \zeta=0.56 \%\end{array}$ & $17 \% \uparrow$ & $1.7 \% \downarrow$ & $\downarrow$ & - \\
\hline Willford, 2002 [2] & - & $\begin{array}{c}\text { Millennium Bridge } \\
f=1.18 \mathrm{~Hz}, \zeta=0.8 \%\end{array}$ & $\uparrow$ & - & $\downarrow$ & - \\
\hline Brownjohn, 2004 [40] & Up to 150 & $\begin{array}{l}\text { Changi Mezzanine steel footbridge } \\
\qquad f=4.44 \mathrm{~Hz}, \zeta=0.7 \%\end{array}$ & Up to $100 \% \uparrow$ & - & $\downarrow$ & - \\
\hline $\begin{array}{l}\text { Brownjohn and } \mathrm{Fu}, 2005 \\
\text { [41] }\end{array}$ & $1-35$ & $\begin{array}{l}\text { Singapore Polytechnic steel footbridge } \\
\qquad f=4.72 \mathrm{~Hz}, \zeta=0.85 \%\end{array}$ & $100 \%-500 \% \uparrow$ & $7 \% \uparrow$ & $\downarrow$ & - \\
\hline Živanović et al., 2009 [11] & $2-10$ & $\begin{array}{l}\text { Posttensioned lab footbridge } \\
f=4.44 \mathrm{~Hz}, \zeta=0.72 \%\end{array}$ & $297 \% \uparrow$ & $1.6 \% \uparrow$ & $38 \% \downarrow$ & - \\
\hline Živanović et al., 2010 [4] & 6.1 pedestrians/min & $\begin{array}{l}\text { Podgorica steel footbridge } \\
f=2.04 \mathrm{~Hz}, \zeta=0.26 \%\end{array}$ & $158 \% \uparrow$ & $2 \% \downarrow$ & $65 \% \downarrow$ & - \\
\hline Fanning et al., 2010 [42] & $4-30$ & $\begin{array}{l}\text { O'Casey steel footbridge } \\
f=2.01 \mathrm{~Hz}, \zeta=0.5 \%\end{array}$ & $\uparrow$ & - & $20 \% \downarrow$ & - \\
\hline Dong et al., 2011 [43] & $0-2$ pedestrians/s & $\begin{array}{l}\text { Olga cable-stayed footbridge } \\
f=1.80 \mathrm{~Hz}, \zeta=0.5 \%\end{array}$ & $280 \% \uparrow$ & $4.4 \% \downarrow$ & - & - \\
\hline $\begin{array}{l}\text { Georgakis and } \\
\text { Jorgensen, } 2013 \text { [32] } \\
\end{array}$ & $4-10$ & $\begin{array}{c}\text { Steel lab footbridge } \\
f=2.21 \mathrm{~Hz}, \zeta=0.5 \%\end{array}$ & $\uparrow$ & $\downarrow$ & - & - \\
\hline $\begin{array}{l}\text { Shahabpoor et al., 2015; } \\
2016[50,51]\end{array}$ & $3-15$ & $\begin{array}{l}\text { Posttensioned lab footbridge } \\
\qquad f=4.44 \mathrm{~Hz}, \zeta=0.7 \%\end{array}$ & $400 \% \uparrow$ & $1.0 \% \uparrow$ & $32 \% \downarrow$ & - \\
\hline Zhang et al., 2015 [44] & $4-10$ & $\begin{array}{c}\text { Steel lab footbridge } \\
f=2.21 \mathrm{~Hz}, \zeta=0.5 \%\end{array}$ & $\uparrow$ & $\downarrow$ & - & - \\
\hline $\begin{array}{l}\text { Van Nimmen et al., } 2015 \\
\text { [45] }\end{array}$ & $9-21$ & $\begin{array}{l}\text { Eeklo steel footbridge } \\
f=2.99 \mathrm{~Hz}, \zeta=0.2 \%\end{array}$ & $900 \% \uparrow$ & $0-1.5 \% \uparrow$ & - & - \\
\hline
\end{tabular}

not commonly represented in the models. Section 3 describes very limited studies dealing with this category.

The walking human models are divided into three groups here. The first group comprises the linear oscillator models of the human body with a single mass or multiple lumped masses connected together linearly with springs and dampers. The second group comprises the biomechanically inspired inverted-pendulum (IP) models that were developed originally to realistically simulate the human gait. The final group comprises the multibody link-segment models of the human body.

2.2.1. Linear Oscillator Models. Human body dynamics, in the simplest form, can be simulated using an S/MDOF linear model [70]. The first generation of such models simulated the effects of walking on the modal properties of a structure by simply treating them as stationary and rigid masses added to the empty structure $[33,36,71,72]$. This naturally resulted in a decrease of the calculated modal frequency of the structure. However, this method was unable to describe the increased damping and occasional increase in the modal frequency observed in occupied structures [11].

(1) SDOF Models. Archbold [60] used a finite element model to simulate the vertical effects of an SDOF MSD model of a single pedestrian walking across a footbridge structure and compared its results with a force-only model. The parameters of the SDOF walking human model were adopted from biomechanics literature for standing and running people. The initial stiffness of $25 \mathrm{kN} / \mathrm{m}$ and damping coefficient of $800 \mathrm{~N} \cdot \mathrm{s} / \mathrm{m}$ were used in simulations. The Archbold studies showed that when the pacing frequency was close to the modal frequency of the structure, the force-only model overestimated the 10-second RMS of the acceleration response of the structure by $400 \%$, whereas the interactive model estimated the response with a maximum of $10 \%$ error. It was 


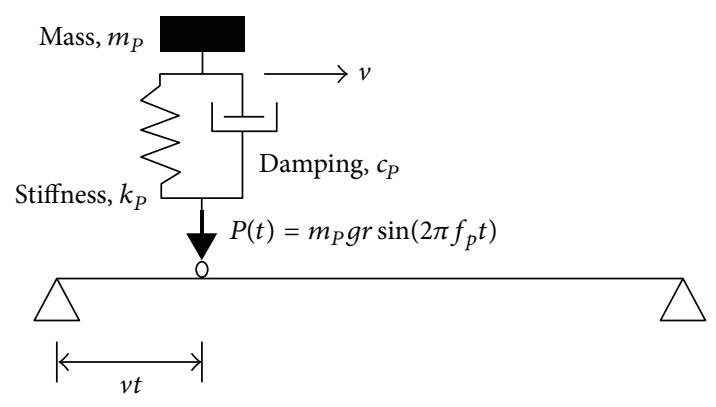

(a)



(b)

FIGURE 3: (a) Moving mass-spring-damper model coupled with walking GRF and (b) ratio of the response of interactive/force-only models [47].

also found that including the higher harmonics of the walking force in the simulation did not improve the accuracy of the results.

Fanning et al. [61] used a moving SDOF MSD model coupled with a single harmonic walking GRF to simulate the effects of a walking pedestrian on an Aberfeldy glass fiber reinforced concrete (GFRC) footbridge. An extensive set of tests were carried out on Aberfeldy footbridge with firstvertical mode of $1.54 \mathrm{~Hz}$, where nine test subjects walked on the bridge one at a time, both with and without controlled pacing frequency. The analysis by Fanning et al. [61] showed that force-only models produced response errors of up to $200 \%$ when the structure was excited at resonance. The parameters of the MSD SDOF model were optimised so that the estimated response matched the corresponding measured ones. Fanning et al. [61] suggested $k_{h}=7.5 \mathrm{kN} / \mathrm{m}$ and a velocity dependent damping model in the form of $c_{h}$ $(\mathrm{N} \cdot \mathrm{s} / \mathrm{m})=50+2,500 \dot{x}(\mathrm{~m} / \mathrm{s})$ to simulate the human model. Using this model, the errors of the estimated responses reduced to less than $40 \%$ around resonance.

Caprani et al. [47] used a moving SDOF MSD model coupled with a walking force to simulate the effects of a single walking pedestrian on a structure (Figure 3(a)). Only the first harmonic of the walking force was used in the simulations and the range of human model parameters were adopted from the biomechanics literature. A simply supported beam simulated with an SDOF MSD model was used to model the structural dynamics. The response ratio $\mu$ of the two cases of interactive MSD human model and the force-only model was used to analyse the effects of HSI on the structural response (Figure 3(b)).

The mass and stiffness of the MSD model were varied within ranges of $10-130 \mathrm{~kg}$ and $10-35 \mathrm{kN} / \mathrm{m}$, respectively, with a constant damping ratio of $30 \%$, pacing frequency of $1.96 \mathrm{~Hz}$, and step length of $0.66 \mathrm{~m}$. Figure 3(b) shows the results of the Caprani et al. study for three bridge natural frequencies, $1.94 \mathrm{~Hz}, 2.0 \mathrm{~Hz}$, and $2.1 \mathrm{~Hz}$. It was found that structural responses away from resonance were similar for both force-only and SDOF models. However, when the SDOF MSD natural frequency was close to that of the structure, the response of the interactive model was considerably lower in comparison with the force-only simulation. It was suggested that the resulted response ratios $\mu$ can be used for finding the interactive response of structures using the force-only response. The work of Caprani et al. features a sound and straightforward analytical methodology, but it lacks experimental validation. An extensive experimental validation is particularly important to analyse the generality of the suggested response ratio due to inter- and intrasubject variability and the amplitude dependency of the human model parameters (such as modal frequency and damping ratio).

Archbold et al. [62] used the same model as Caprani et al. [47] but investigated in more detail the effects of the pacing frequency and stride length on the response of a structure. The statistical distributions suggested in the biomechanics literature were adopted to define the parameter of the MSD walking human model. The pedestrian mass was taken to follow a log normal distribution [73] with a mean of $73.9 \mathrm{~kg}$ and variance of $21.2 \%$. The stride length was taken to be normally distributed, with a mean of $0.66 \mathrm{~m}$ and a $10 \%$ variance [74]. The pacing frequency was also considered to be normally distributed, with the mean of $1.96 \mathrm{~Hz}$ and standard deviation of $0.209 \mathrm{~Hz}$ [75-78]. Similarly, the pedestrian stiffness was taken to be normally distributed with a mean of $22.5 \mathrm{kN} / \mathrm{m}$ and a standard deviation of $2.25 \mathrm{kN} / \mathrm{m}$ [79]. Their study showed that the response ratio $\mu$ was extremely sensitive to even slight variations in the pacing rate when it was close to the natural frequency of the structure. It was also found that variations in the step length had little effect on the structural response.

The work of Silva and Pimentel [63] is a rare example that proposes a range of parameters for the SDOF walking human model in the context of structural vibration serviceability. They identified the parameters of an SDOF MSD walking human model by analysing the correlation of the walking force and the acceleration of the human body recorded at the waist.

In total, 20 test subjects, 11 men and nine women, took part in their experiments, where they walked at their desired 
speed on a rigid surface. Silva and Pimentel [63] proposed three empirical equations for the mass $(m)$, damping $(c)$, and stiffness $(k)$ of the SDOF human model:

$$
\begin{aligned}
m & =97.082+0.275 \times M-37.518 \times f_{p}, \\
c & =29.041 \times m^{0.883}, \\
k & =30351.744-50.261 \times c+0.035 \times c^{2},
\end{aligned}
$$

where $M[\mathrm{~kg}]$ is the total mass of the human body, $f_{p}[\mathrm{~Hz}]$ is the pacing frequency, and $m[\mathrm{~kg}], c[\mathrm{~N} \cdot \mathrm{s} / \mathrm{m}]$, and $k[\mathrm{~N} / \mathrm{m}]$ are the human SDOF model mass, damping, and stiffness, respectively. The work of Silva and Pimental [63] used a solid and innovative approach common in the system identification of mechanical systems, to estimate the parameters of a walking human model. However, a simplistic threeharmonic synthetic walking GRF (rather than the measured GRF) was used for the system identification. The initial ranges of the human SDOF model stiffness and damping values were adapted from the standing people parameters, which might not accurately represent the walking people. For instance, it was assumed that the damping of a walking person is lower than the damping of the same person standing.

Silva et al. [48] used the moving SDOF oscillator model developed earlier by Silva and Pimentel [63] to simulate the effects of nonsynchronised multipedestrian walking traffic on the vibration response of structures and compared it with full-scale measurements. Silva et al. [48] used two methods to simulate walking pedestrians. In the first method, both the walking force and the walking people model moved together along the structure. This method is nonlinear and time-varying, as the location of the human DOF on the structure changes with time. In the second method, only the walking force moved along the structure and the location of the human model was kept constant. Pedestrians in this method were distributed evenly along the structure. A simply supported concrete prototype footbridge, with a clear span of $11.30 \mathrm{~m}$ and width of $1.8 \mathrm{~m}$, was used for the study. The modal tests showed that the first-vertical mode of the structure had $4.27 \mathrm{~Hz}$ natural frequency and $1 \%$ damping ratio. Three tests, involving 12, 31, and 48 walking test subjects (pedestrian densities of $0.3,0.7$, and 0.9 pedestrians $/ \mathrm{m}^{2}$ ), were carried out. The spectrum of the experimental and analytical acceleration response of the structure is presented in Figure 4 for these three tests.

Silva et al. [48] observed a slight reduction in the natural frequency of the structure and a considerable reduction in the response of the structure (increased damping) when using a human dynamic model (both methods). These effects were increased as the number of walking people on the structure increased. None of these effects were evident in the response of the structure excited by the force-only model. This work, however, again used the simplistic three-harmonic synthetic walking GRF rather than measured GRF.

Shahabpoor et al. [52] adopted a single-degree-offreedom (SDOF) MSD oscillator model to simulate interaction of a single walking pedestrian with vibrating structures (Figure 5).
They performed an extensive parametric study and found that when the natural frequency of the human model $f_{h}$ was less than that of the empty structure $f_{s}$, the natural frequency of the occupied structure $f_{\text {os }}$ was higher than $f_{s}$ (Figure 6(a), red FRF moduli graphs). Figure 6(a) also shows that when $f_{h}$ is greater than $f_{s}$, the natural frequency of the occupied structure $f_{\text {os }}$ is less than that of the empty structure $f_{s}$. The closer the natural frequencies of the human and the structure, the greater the change in $f_{\text {os }}$ and $\zeta_{\text {os }}$. Shahabpoor et al. [52] also found that an increase of damping of the human model $\zeta_{h}$ results in an increased damping ratio of the occupied structure $\zeta_{\text {os }}$ (Figure 6(b)). As mentioned in Section 2.1, these findings shed light on the probable mechanism behind the change of the modal properties of real-world structures occupied by walking pedestrians reported in the literature [11].

Shahabpoor et al. [64] later carried out a sensitivity analysis on a similar 2-DOF human-structure system and found that when the natural frequency of the human model $f_{h}$ was less than the natural frequency of the structure $f_{s}$, both the natural frequency $f_{\text {os }}$ and damping ratio $\zeta_{\text {os }}$ of the occupied structure were more sensitive to the human model stiffness. On the other hand, when $f_{h}$ is greater than $f_{s}$, both $f_{\text {os }}$ and $\zeta_{\text {os }}$ are more sensitive to the human model mass $m_{h}$. It was also found that $f_{\text {os }}$ is not sensitive to $\zeta_{h}$, while $\zeta_{\text {os }}$ shows the highest sensitivity to $\zeta_{h}$ when the natural frequencies of the human body SDOF and the empty structure are equal. Both Shahabpoor et al. $[52,64]$ studies use a solid and practical modelling strategy with minimal presumptions; however, both works lack experimental validation. Moreover, multipedestrian interaction and the effects of the timevarying location of walking pedestrians on the structure were not considered in their studies.

Jiménez Alonso and Sáez [65] used a 3-DOF model, comprising three independent SDOF MSDs to simulate the interaction of a walking human with a structure in three dimensions. They used the experimental data reported by Georgakis and Jorgensen [32] in an inverse dynamics procedure to identify the parameters of the SDOF human model in the vertical direction by trial and error. The initial ranges of human model mass (80-100\% of total body mass), damping ratio $(10-69 \%)$, and natural frequency $(1.00-10.43 \mathrm{~Hz})$ were adopted by analogy from the range of parameters reported in literature for a standing human. Results of Jiménez Alonso and Sáez [65] study suggested that an SDOF MSD model with a mass equal to $84 \%$ of total body mass, damping ratio of $47 \%$, and natural frequency of $2.75 \mathrm{~Hz}$ can simulate the dynamic effects of a walking human on structures with low sensitivity of response to small changes of human body parameters. Their work, however, did not provide any details on the analysis procedure, error tolerances, and the methodology used to simulate the stream of pedestrians on the structure.

Recently, Zhang et al. [44] carried out a set of FRFbased modal tests on a full-scale laboratory footbridge, with a natural frequency of $2.2 \mathrm{~Hz}$ and modal damping ratio of $0.5 \%$, first empty and then occupied by groups of 4,7 , and 10 walking pedestrians. An SDOF MSD model was used to simulate the interaction of pedestrians with the structure. 


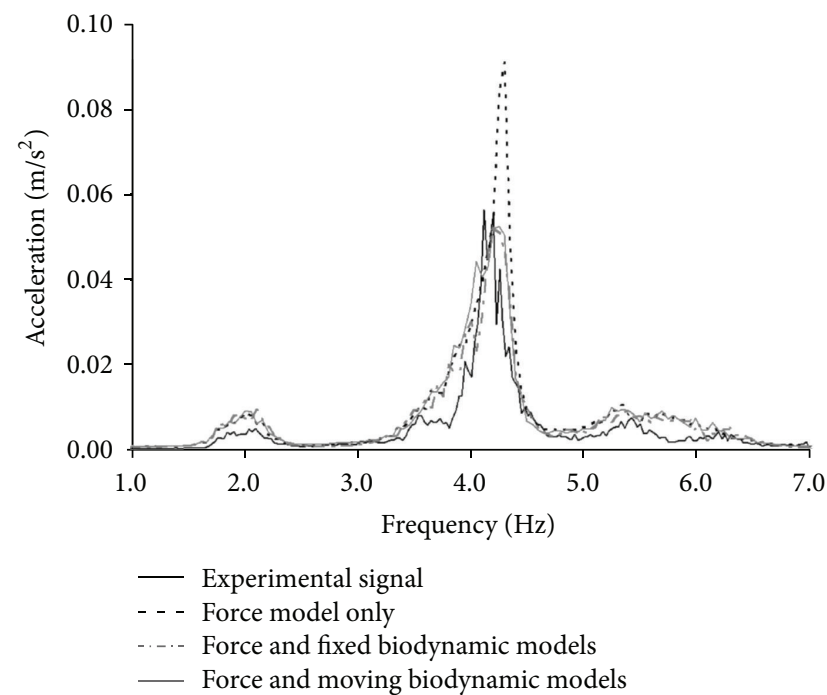

(a) Density of 0.3 pedestrians $/ \mathrm{m}^{2}$

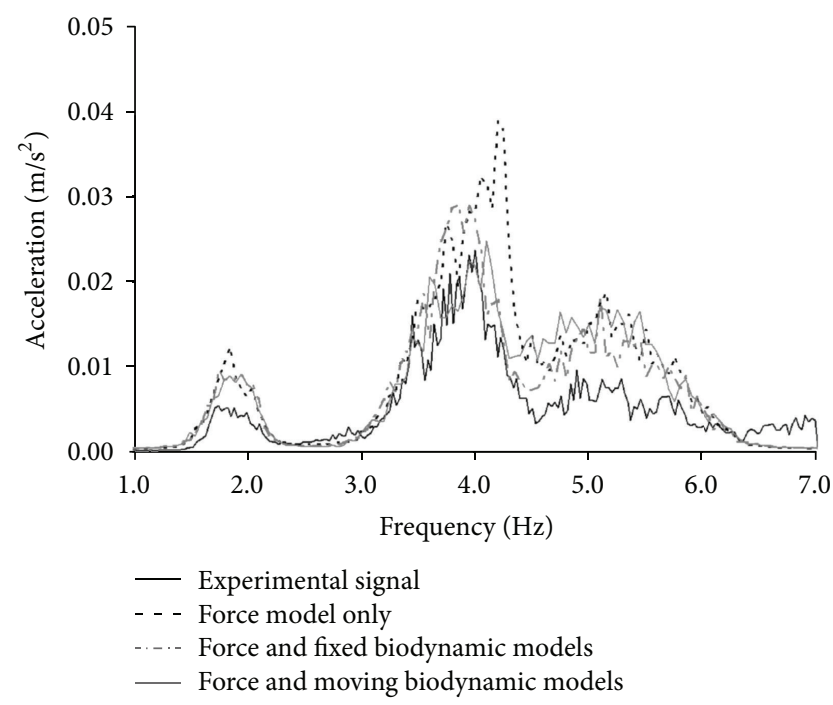

(b) Density of 0.7 pedestrians $/ \mathrm{m}^{2}$

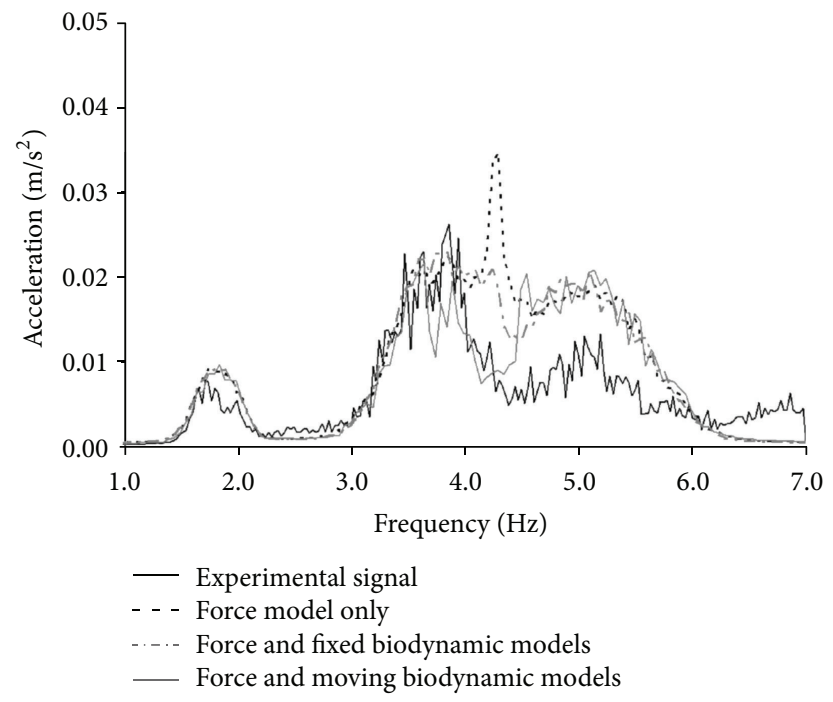

(c) Density of 0.9 pedestrians $/ \mathrm{m}^{2}$

FIGURE 4: Mean response spectra [48].

The parameters of the walking SDOF model were identified by fitting the measured FRFs in tests with their simulated counterparts. Zhang et al. [44] reported the natural frequency and damping ratio of the SDOF walking human model to be $1.85 \mathrm{~Hz}$ and $30 \%$, respectively. The work of Zhang et al. used a well-established FRF-based identification methodology. However, it lacked independent experimental verification and did not take into account the walking forces in calculation of measured FRFs.

Živanović [80] carried out a set of nine tests on a $63 \mathrm{~m}$ FRP bridge, where six test subjects crossed the bridge one at a time. The natural frequency and modal damping ratio of the footbridge were $1.5 \mathrm{~Hz}$ and $0.4 \%$, respectively. The parameters of an SDOF MSD walking human model were then identified by matching the estimated peak response with the corresponding measured peak responses. Using the total mass of the participant, the ranges of $1.0 \mathrm{~Hz}-2.6 \mathrm{~Hz}$ and
$10-27 \%$ were identified for the natural frequency and damping ratio of the walking human model.

Zhou et al. [81] used an integrative model to simulate a human on a structure. Rather than modelling the human body as a lumped mass connected to a spring and damper, they assumed it to be a continuous two-segment bar with distributed mass $m(x)$, stiffness $k(x)$, and damping $c(x)$ represented as an SDOF on the structure. It was found that the undamped and damped natural frequencies of the first mode from the integrative model were always smaller than those from the conventional MSD models. The work by Zhou et al., however, lacks experimental verification and does not suggest any particular parameter for the human model.

Shahabpoor et al. [51] used a discrete model of humanstructure system to simulate the interaction of multipedestrian walking traffic with the vibrating structure. Each 


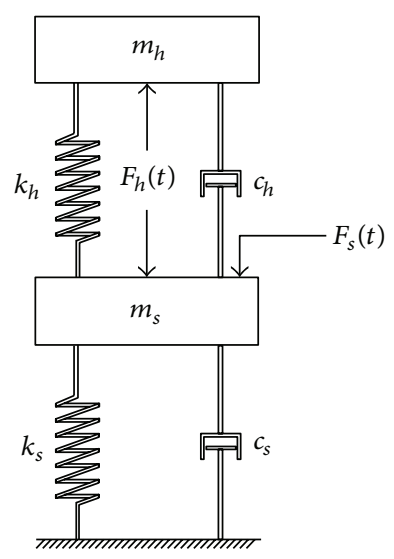

(a)

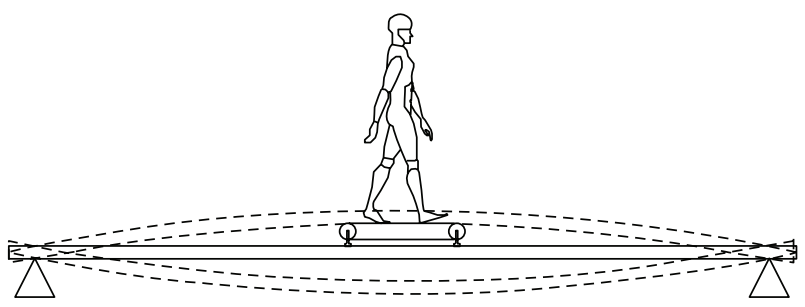

(b)

FIGURE 5: (a) The mathematical 2-DOF model of human-structure system and (b) the conceptual representation of a stationary human walking on the structure.

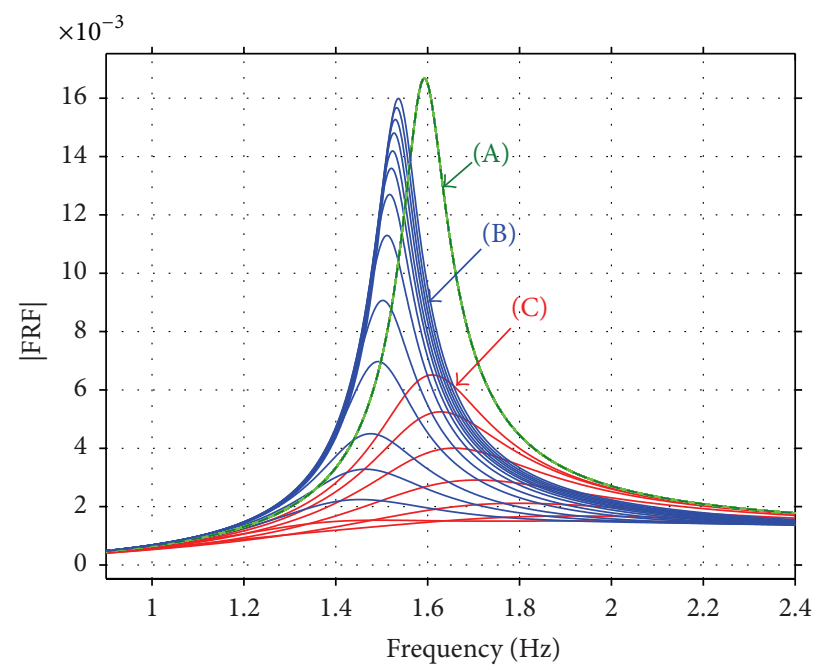

(a)

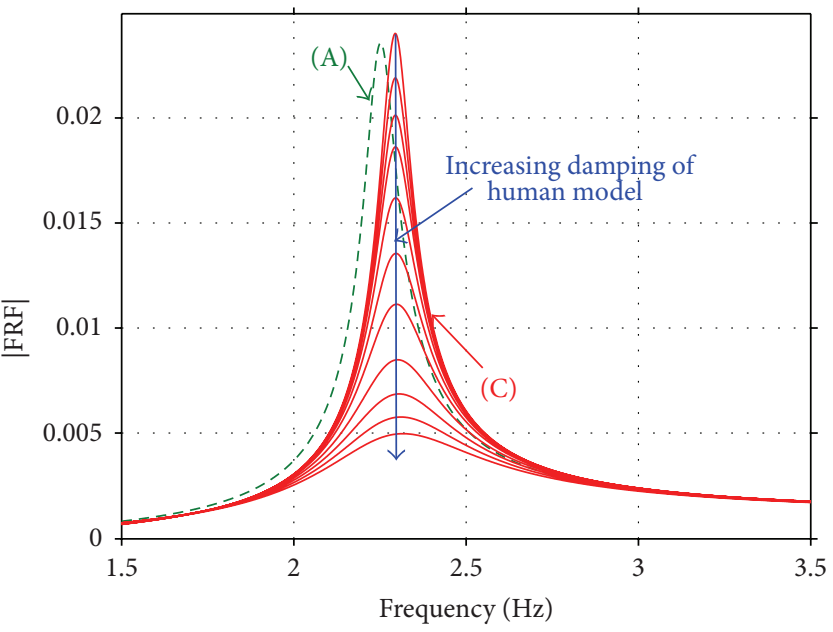

(b)

FIGURE 6: Effects of (a) walking human natural frequency and (b) damping ratio on structure FRF. (A) Empty structure; (B) $f_{h}>f_{s}$; (C) $f_{h}<f_{s}$.

walking human was modelled using an SDOF MSD model (Figure 7). The structure was also modelled with an SDOF model representing a mode of its vibration. The analysis identified the range of $2.75-3.00 \mathrm{~Hz}$ for the natural frequency and $27.5-30 \%$ for the damping ratio of the SDOF model of a walking human, having a constant mass of $70 \mathrm{~kg}$. The identification procedures used in this study modelled the time-varying location of walking pedestrians on the structure with an increasing level of detail and complexity. However, in all of these procedures, human body was assumed to be "stationary" while walking.

Toso et al. [66] used a similar methodology to Silva et al. [48] and measured the spectral acceleration amplitudes of the first-three harmonics of 35 test subjects at their waist level and the amplitudes of the first-three harmonics of the corresponding vertical ground reaction force. They used the artificial neural network (ANN) to relate the biodynamic parameters to the pacing rate and the body mass of the pedestrians:

$$
\begin{aligned}
m\left(f_{p}, M\right)= & -231.34+3.69 M+154.06 f_{p} \\
& -1.97 M f_{p}+0.005 M^{2}-15.25 f_{p}^{2}, \\
c(M, m)=- & 1115.69+92.56 M-108.94 m \\
& +2.91 M m-1.33 M^{2}-1.30 m^{2}, \\
k\left(M, f_{p}\right)= & 75601.45-1295.32 M-33786.75 f_{p} \\
& +506.44 M f_{p}+3.59 M^{2}+539.39 f_{p}^{2},
\end{aligned}
$$

where $M[\mathrm{~kg}]$ is the total mass of the human body, $f_{p}[\mathrm{~Hz}]$ is the pacing frequency, and $m[\mathrm{~kg}], c[\mathrm{~N} \cdot \mathrm{s} / \mathrm{m}]$, and $k[\mathrm{~N} / \mathrm{m}]$ are the human SDOF model mass, damping, and stiffness, 


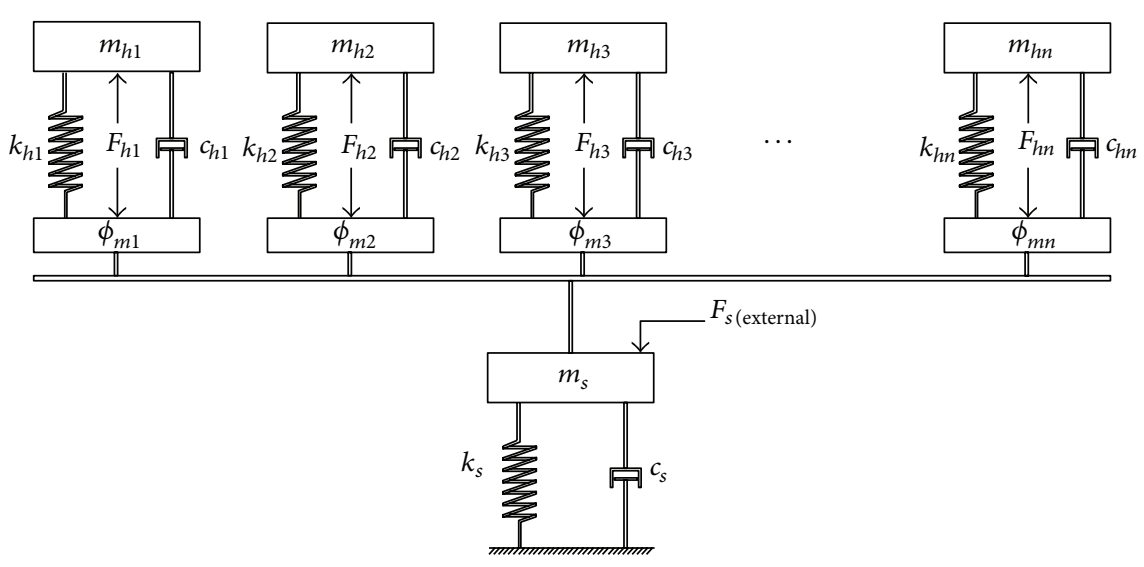

FIGURE 7: The mechanical model of a walking people-structure system simulated as an stationary system.

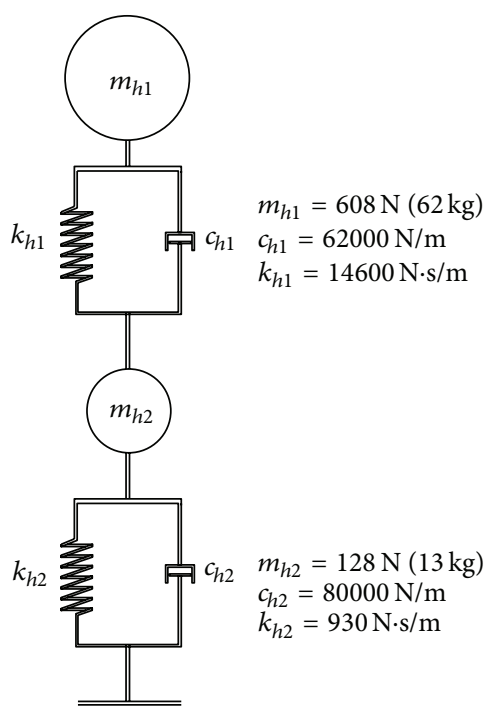

FIGURE 8: Human body model [49].

respectively. The study of Toso et al. [66] provides an invaluable insight into the ranges of SDOF walking human parameters. It improved the accuracy of the identification procedure compared to Silva et al. [48] by using measured free field walking forces, utilising a specially constructed force platform instead of synthetic forces. This work, however, was carried out for a single pedestrian and, therefore, does not include the multipedestrian traffic challenges. The acceleration recorded at the pelvis location was not reoriented to the earth coordinate system, which could potentially introduce errors in calculations due to the rotation of pelvis.

(2) MDOF Models. Kim et al. [67] used a 2-DOF MSD model to simulate a walking individual in the vertical direction. They adopted the human model parameters mostly from ISO 5982:1981 [49] developed for standing people (Figure 8). The effect of a single walking pedestrian was simulated on a $99 \mathrm{~m}$ long cable-stayed footbridge located in a Seoul park, South Korea, with an empty natural frequency of $1.88 \mathrm{~Hz}$ and a modal damping ratio of $0.4 \%$. The response of the structure was compared for two scenarios of the passive moving force and interactive 2-DOF human model. Surprisingly, it was found that the response of the structure using an interactive 2-DOF model was $34 \%$ higher than that of the force-only model.

Finally, Miyamori et al. [82] simulated a walking pedestrian with a 3-DOF oscillator model, but no comparison was presented with a force-only case to examine the performance of their model.

2.2.2. Inverted-Pendulum Models. Inverted-pendulum models (IPMs) are traditionally used in biomechanics literature to simulate the walking gait in detail $[80,83]$. IPMs have been shown to provide high fidelity replication of the dynamics of the human locomotor system, simulating both temporal and spatial gait parameters, such as stride length, pacing frequency, centre of mass (CoM) motion, timing of gait events such as heel strike and toe off, and the required propulsive energy to maintain a specific gait pattern [8486]. Several different variants of IPMs have been proposed in the literature to simulate walking, ranging from a simple IPM comprising a point mass and a solid leg [87] to more complex ones with spring and damper legs (Figure 9) [54]. Other variations include IPMs with roller feet and bipedal IPMs to simulate the double-support phase of the gait more accurately (Figure 9) $[86,88]$. The spring and damper in the legs help simulate the dynamics of legs more realistically, while foot models attached to IPM such as roller feet model help simulate different phases of foot-ground contact during the gait realistically.

Some of the key benefits of using IPMs for simulating HSI are the more realistic modelling of body dynamics and the possibility of investigating the effects of structural vibrations on gait parameters such as pacing rate and walking speed. Moreover, IPMs can model both components of the interaction force, that is, GRF on a stiff surface and HSI effects. A 3D IPM can simulate HSI simultaneously in all three directions. This provides the opportunity for more advanced modelling approaches to investigating the effects of HSI in one direction on other directions.

The application of IPMs for HSI simulation, however, has some drawbacks. IPM is essentially a nonlinear system 

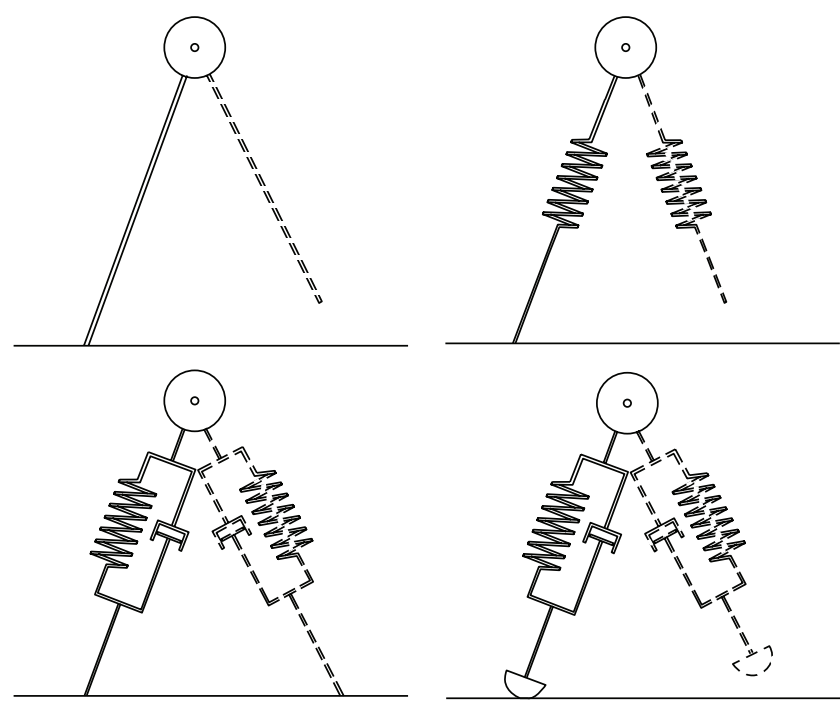

FIGURE 9: IPM models suggested in literature to model a walking human.

and the superposition principle does not apply to it. The behaviour of IPMs is harder to analyse and, therefore, less practical for day-to-day design practice. While a linear SDOF MSD model needs only three parameters $(m, c$, and $k)$ to be defined, similar IPMs need a minimum of six independent parameters such as body mass, angle of attack, length of leg at rest, leg stiffness, leg damping ratio, and initial system energy and, in the case of more complex models, feet model parameters and model stability margins [55]. This might indicate the higher versatility of IPMs, but it also increases considerably their indeterminacy and decreases their robustness, particularly due to the high inter- and intrasubject variability of their input parameters.

Several researchers have adapted IP models from the biomechanics literature, to simulate the interaction of walking pedestrians with civil structures, particularly in the lateral direction. However, their application to modelling HSI in the vertical direction is rare. Bocian et al. $[53,68]$ used a massonly IP model to simulate the motion of the body CoM in a walking person. They studied the gait adaptation strategies of the human model when subjected to a vertical base excitation. The equation of motion of the inverted-pendulum model (Figure 10) during the single support phase was easily derived by applying D'Alembert's principle:

$$
\ddot{\theta}=-\frac{1}{l}(g+\ddot{z}) \cos \theta,
$$

where $\theta$ is the supporting leg inclination angle; $l$ is equivalent inverted-pendulum length; $g$ is gravitational acceleration; $z$ is the vertical displacement of the bridge; and dots over the symbols represent derivatives with respect to time. In Figure $10, F_{v}$ is the vertical component of the interaction force and $m_{p}$ is the mass of a pedestrian.

Bocian et al. found that, depending on the ratio of the pedestrian pacing frequency and the base excitation frequency, a walking human can either increase or decrease the damping of the structure. Similar to the conclusions with

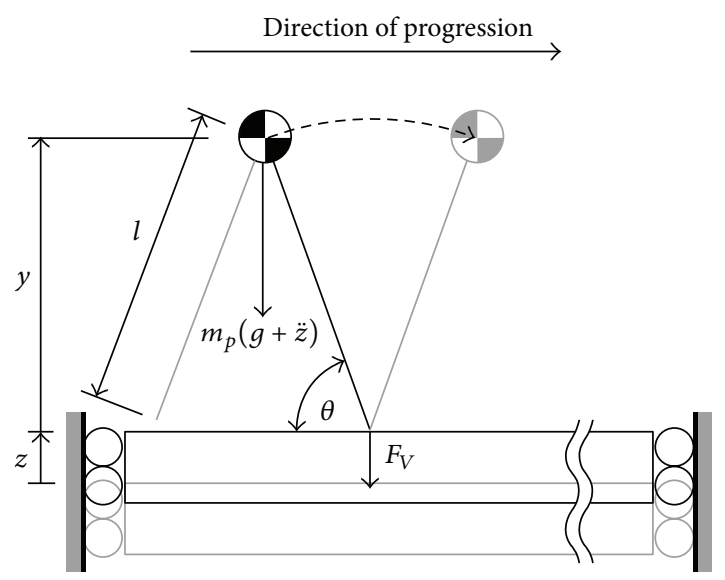

FIGURE 10: Inverted-pendulum walking human model on a vertically vibrating structure [53].

linear MSD models described in Section 2.2.1, Bocian et al. concluded that, for a multipedestrian walking traffic, the overall effect of the pedestrians is more likely to manifest itself as an increase in damping ratio and mass of the structure. This occurs due to the base motion, subtly altering the timing of the footfall impulses to bias the net effect, but without actually causing synchronisation of the pedestrian with the base frequency. The results of Bocian et al. [53, 68] studies were quite interesting, but their IPM was too simple and no experimental validation was provided. Using bipedal IPM with springs and damper can significantly increase the biofidelity of the model.

Dang and Živanović [69] compared the performance of a moving harmonic force model, a moving oscillator-actuator model, and an inverted-pendulum model (without spring and damper) in reproducing kinematic and kinetic features of a walking human and replicating the vibration patterns observed on a lively footbridge. The structure selected for the study was a light cable-stayed bridge made of fiber reinforced polymer, with the length of $113 \mathrm{~m}$, the main span of $63 \mathrm{~m}$, and the weight of $20,000 \mathrm{~kg}$. The structure was very alive, with a fundamental vibration mode at $1.52 \mathrm{~Hz}$, a $2,750 \mathrm{~kg}$ modal mass, and a $0.42 \%$ modal damping ratio.

The inverted-pendulum model DLF, mass, average walking speed, and pacing frequency were selected to be equal to $0.14,86 \mathrm{~kg}, 1.43 \mathrm{~m} / \mathrm{s}$, and $1.52 \mathrm{~Hz}$, respectively, based on the tests carried out on the footbridge. The SDOF MSD human model's natural frequency, damping ratio, and DLF were selected to be equal to $2.3 \mathrm{~Hz}, 8 \%$, and 0.1 , respectively, by an analogy with the properties of the bouncing people found in the literature. However, no justification or validation was presented for this analogy.

The study of Dang and Živanović [69] showed that a traditional force-only model cannot predict the response of the structure accurately in lightweight structures where HSI has a prominent contribution. Both the inverted-pendulum and SDOF MSD oscillator models predicted the interaction level acceptably, while the IPM could better replicate the kinematics of the human body's CoM. The IPM could also 


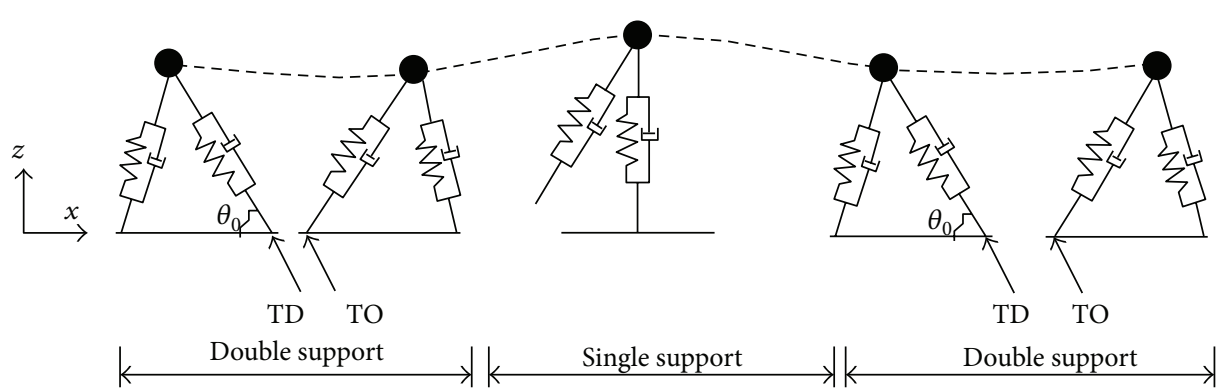

(a)

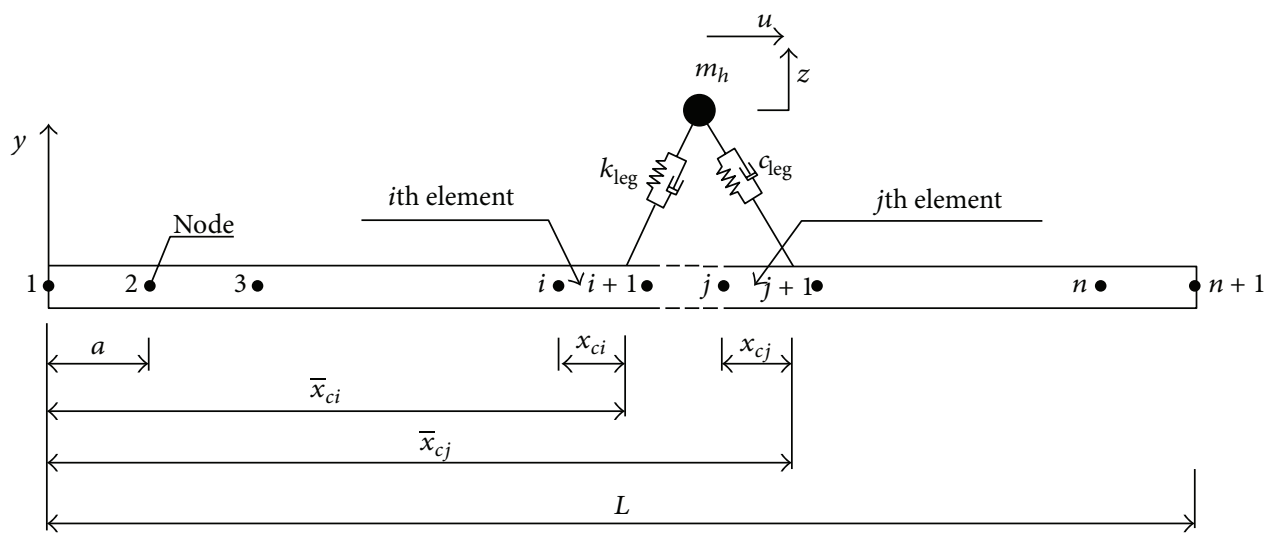

(b)

FIGURE 11: The schematics of Qin et al. (a) [54] and (b) [55] biomechanical walking model (TD: touchdown of leading leg; TO: toe off of the trailing leg).

simulate the effects of the structure on the pacing frequency and phase of the walking force.

Qin et al. [54] used a bipedal IP walking model with damped compliant legs to simulate a walking human. Their bipedal model had two degrees of freedom ( $x$ and $z$ on Figure 11(a)) and the mass was concentrated at CoM. A massless linear spring and a time-varying damper connected in parallel were used to simulate each leg (Figure 11(a)). The time-varying damping mechanism was employed to simulate realistically the ground reaction force, especially at the touchdown of the leading leg. A control force in a feedback form was applied to the pedestrian in each walking step, to compensate for the energy dissipated by the damping of the model and to regulate the walking behaviour.

Qin et al. [54] studied the effects of leg stiffness and damping and the landing angle of attack of the leading leg $\theta_{0}$ (Figure 11(a)) on the response of the structure. The results of their investigation showed that the level of interaction increased by increasing the magnitude of the structural vibration. Therefore, more feedback energy was required to maintain the steady walking. Leg stiffness was found to have a significant effect on the dynamic response of the structure, when the step frequency was close to the natural frequency of the structure.

Qin et al. [55] used a bipedal IPM to simulate the interaction of a walking pedestrian with a beam structure. The human IPM had two DOFs, $u$ and $z$, as shown in Figure $11(\mathrm{~b})$. The human body mass $\left(m_{h}=80 \mathrm{~kg}\right)$ was considered to be lumped at the CoM. Each leg was modelled using a massless linear spring $\left(k_{\text {leg }}=20 \mathrm{kN} / \mathrm{m}\right)$ to provide a compliant mechanism to absorb heel strike impacts and to generate push-off impulses and a time-variant nonlinear damper $(\zeta=8 \%)$ to restrain the excessive motion of the CoM. A longitudinal feedback control force was applied to the CoM at each walking step, to compensate for the energy loss in dampers and to regulate the walking performance of the pedestrians.

Qin et al. [55] carried out a parametric study to analyse the effects of leg stiffness, the angle of attack of the leading leg, the leg damping ratio, and the mass ratio of the human and structure on the response of the structure. They found maximum acceleration response of the structure when the leg stiffness resulted in a pacing frequency close to the natural frequency of the structure (resonance) (Figure 12(a)). They also found that the higher the human/structure mass ratio was, the higher the interaction effects were (Figure 12(b)). The analysis of the damping of the human legs showed that it had no considerable effects on the structural response.

Qin et al. [54, 55] studies are quite unique in using a complex, but highly realistic, bipedal IPM with compliant damped legs to simulate a walking human. Their research, however, was focused on the analytical study of a single pedestrian and did not include any experimental validation. To the best of the authors' knowledge, the IPM parameters were not identified for this HSI application and Qin et al. had to adapt the parameters from biomechanics literature. 


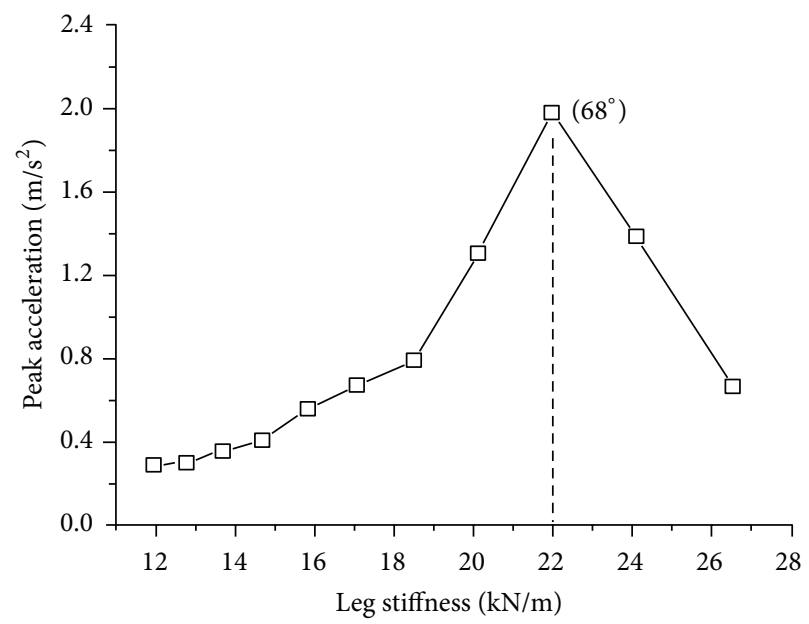

(a)

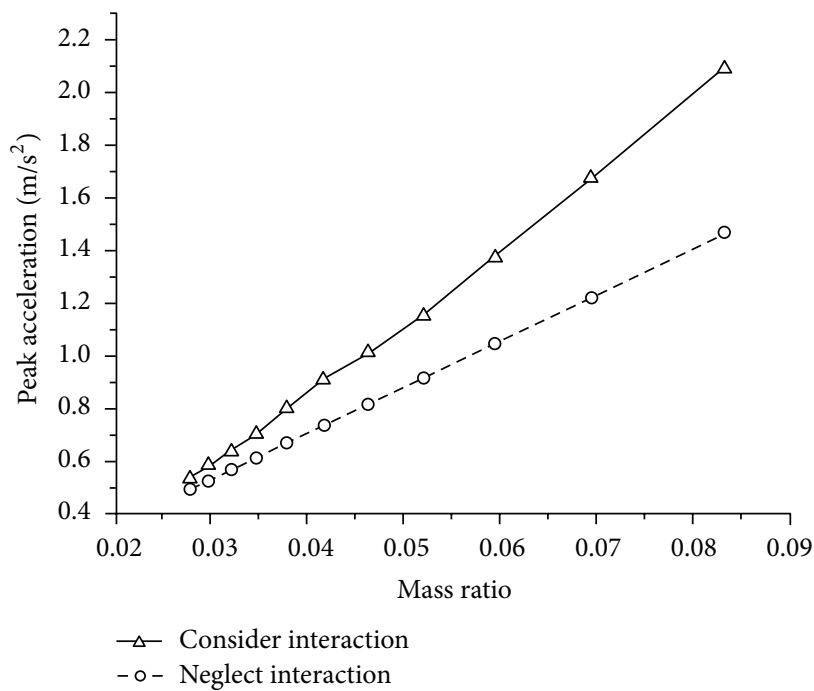

(b)

FIGURE 12: Effect of leg stiffness (a) and human/structure mass ratio (b) on the response of the beam structure.

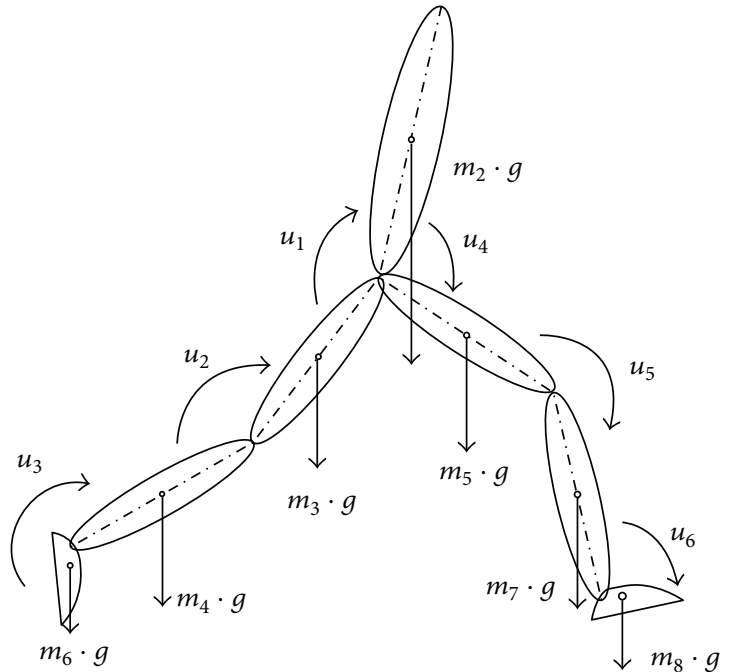

(a)

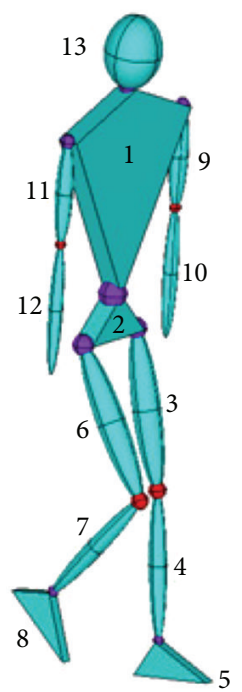

(b)

FIGURE 13: The 2D walking human model, comprising 8 bodies and 9 DOFs (a) and the 3D walking human model, with 13 rigid bodies and 34 DOFs [56].

Common to studies featuring IPM simulations, a large number of assumptions were necessary, such as the nonlinear damping model of the legs in both single- and double-support phases, the regulatory control force to maintain the steady walking gait, and the initial energy input. These assumptions can reduce the generality of the outputs. Some of the results of Qin et al's study, such as the considerable increase in the response of the structure when considering HSI and the negligible effects of the walking human on modal properties of the empty structure, contradict experimental evidence from the real-world structures discussed in Section 2.1.

2.2.3. Whole Body Link-Segment Models. Maca and Valasek [56] employed two complex 2D and 3D multibody models of walking human to simulate HSI. They used a 2D model with 9 degrees of freedom for vertical interaction (Figure 13(a)) and a 3D model with 34 degrees of freedom to simulate simultaneous interactions in both vertical and lateral directions (Figure 13(b)). This was the first and only instance that the interaction between a walking human and a structure was simulated in this way for both directions simultaneously.

A combination of feedback and feedforward control algorithms was used in multibody models to replicate normal walking motion and gait. A finite element model (FEM) of a structure was coupled with the human models, and their interaction was simulated on one another at each moment in time using their interaction force. Maca and Valasek [56] concluded that the response of the bridge was affected by the 
ratio of the pacing frequency and natural frequency of the structure and that the number of pedestrians on the structure had no effects on its response. The Maca and Valasek models are very versatile, but the complexity of the models and the high number of input parameters and control assumptions make them hard to analyse and use in day-to-day practice. No experimental verification was provided for the models.

2.2.4. Comparison of Human Model Parameters. The parameters of the linear oscillator and IP models used to simulate the interaction of a walking human in literature are summarised in Tables 3 and 4, respectively. As can be seen in Table 3, $f_{h}$ covers a range of $1.85-3 \mathrm{~Hz}$ and $\zeta_{h}$ covers a range of $27.5 \%-47 \%$. The adopted parameters for IPMs are $65^{\circ}-80^{\circ}$ for the angle of attack of the leading leg, $16-23 \mathrm{kN} / \mathrm{m}$ for the leg stiffness $k_{h}$, and 3-8\% damping ratio $\zeta_{h}$. An interesting difference is between the lower values of the damping ratio $\zeta_{h}$ in IPMs compared to MSD models.

\section{Effects of Structural Vibrations on Walking Human}

Humans have an intelligent sensory-motor system that constantly adapts body movements to the environment and reacts to external stimuli consciously or subconsciously. Structural vibrations as a stimulus can trigger such conscious and subconscious reactions and adaptations. An example of such reactions is the coactivation of a pair of antagonistic muscles to increase the stiffness of specific leg joints in reaction to a disturbing base vibration [89]. Two categories of effects of structural vibrations on a walking human are discussed in this section. The first category discusses the lock-in phenomenon, which in turn describes the tendency of pedestrians to synchronise their pacing frequency with the structural vibrations. In some cases, lock-in may trigger synchronisation [90], which is more a matter of a humanhuman interaction. The second category discusses the effects of structural vibrations on the parameters of the walking human model.

3.1. Lock-In. Bachmann and Ammann [91] argued that vertical vibrations with an amplitude higher than $10-20 \mathrm{~mm}$ can force walking pedestrians to adjust their pacing rate with the motion of a vibrating structure. Grundmann et al. [57] suggested a method to take into account the probability of synchronisation of people with the vertical vibration of the structure. They defined the probability of synchronisation $P_{S}\left(a_{g}\right)$ as a function of the acceleration amplitude of the structure $a_{g}$ (Figure 14). In addition, they proposed that the response to $N$ walking people on a structure can be calculated from the following equation:

$$
a_{g}=P_{S}\left(a_{g}\right) N_{r} a_{1 r z}
$$

where $a_{1 r z}$ is the response to a single pedestrian and $N_{r}=$ $N K$ is the number of people reduced by factor $K<1$, which takes into account that the location of the load moves along the structure.

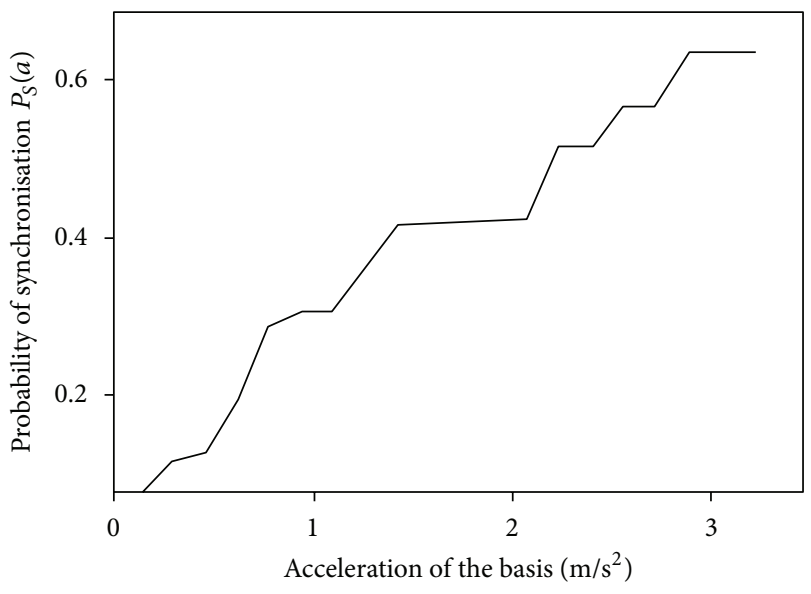

FIgURE 14: Probability of synchronisation as a function of the acceleration of the bridge [57].

However, investigations into the Paris Solferino bridge [92] suggested that lock-in in the vertical direction is unlikely to happen, as pedestrians would be disturbed by the excessive vibration and would not be able to maintain the pacing rate at resonant frequency. The findings of Živanović et al. [93] support this claim when analysing the interactions of three footbridge structures with a single pedestrian walking at or near the resonant frequency. Test subjects were asked to walk once with the aid of a metronome tuned to the natural frequency of the structure and once without the metronome. They found that, in the presence of a strong vibration, pedestrians could not keep a steady pacing frequency and this reduced the chance of a resonant build-up.

Figure 15 shows the simulated (orange) and measured modal responses from the free walking of a single test subject at resonance on two lively footbridges, which moved perceptibly. In both cases, the test subject was asked to walk at resonant frequency without the aid of a metronome. It was found for the two structures that, at $t=35 \mathrm{~s}$ and $26 \mathrm{~s}$ from the beginning of the tests, respectively, the subjects started changing their pacing rate. The perceived vibration levels by test subjects at these points were found to be equal to $0.33 \mathrm{~m} / \mathrm{s}^{2}$ and $0.37 \mathrm{~m} / \mathrm{s}^{2}$, respectively, based on their location on the structure at the time. They concluded that $0.33 \mathrm{~m} / \mathrm{s}^{2}$ and $0.37 \mathrm{~m} / \mathrm{s}^{2}$ are the maximum acceleration magnitudes that a pedestrian can endure in the vertical direction without disturbing their established walking pattern. Živanović et al. [93] further argued that the observed reduction in the response of the structure could be simulated either as a disturbance of the normal walking force or as an increase of damping of the structure. They found that, for the case of the increased damping, the occupied structure damping ratio was up to 10 times higher than that of the empty structure.

The design guidelines for steel footbridges [94], funded by the European Commission, suggest that synchronisation of the human body centre of mass with structural vibration is similar to walking at a pacing rate equal to resonant frequency. The design guidelines [94] experiments showed no stable synchronisation behaviour for vertical vibration 


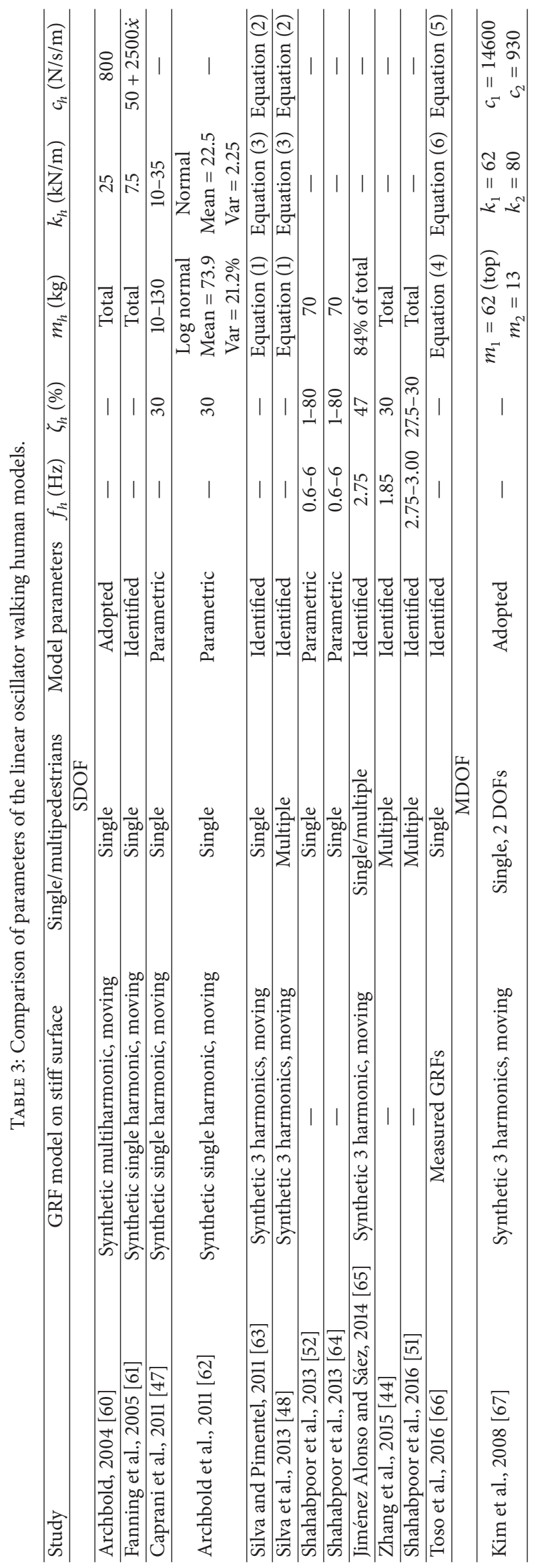




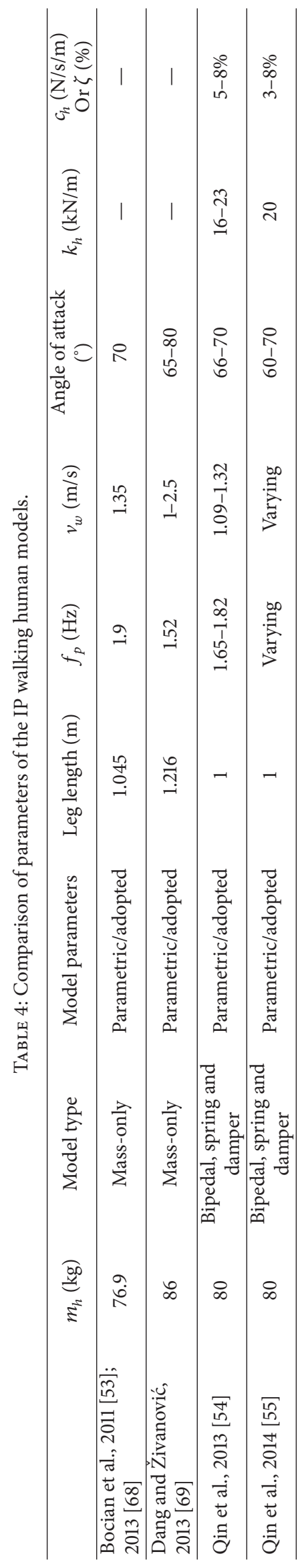






(a)

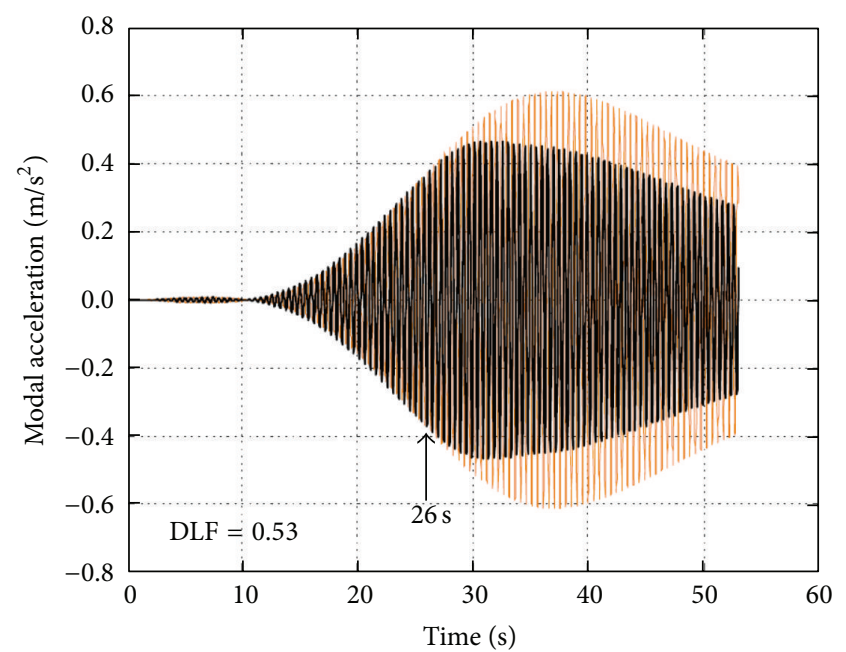

(b)

FIGURE 15: Simulated (orange) and measured modal responses due to free walking at resonance on (a) footbridge 1 (slow pacing rate) at first mode natural frequency of $1.52 \mathrm{~Hz}$ and (b) footbridge 2 (fast pacing rate) at first mode natural frequency of $2.04 \mathrm{~Hz}$ [58].

amplitudes up to $10 \mathrm{~mm}$. It was argued that synchronisation may occur at higher amplitudes, but they would be outside the acceptable limit for the vibration serviceability of a footbridge and pedestrians were very likely to be disturbed or stop walking. They suggested that fast walking persons are almost not affected by the vibration of the deck, as the contact time of the feet with the structure is very short.

\subsection{Effects of Structural Vibrations on Properties of Walking} Human Model. The study of the effects of the level of vibration on the dynamic properties of a human body is limited to stationary people only (standing and sitting) and mostly not in the context of the vibration serviceability of civil structures. Rare studies carried out on standing and sitting people showed that the modal frequency of the human model decreases (the model becomes softer) as the level of vibration increases [95-97]. For instance, Matsumoto and Griffin [96] observed that the modal frequency of standing people increased from 5 to $7 \mathrm{~Hz}$ when the magnitude of the base acceleration root-mean-square (RMS) reduced from $2 \mathrm{~m} / \mathrm{s}^{2}$ to $0.125 \mathrm{~m} / \mathrm{s}^{2}$. These levels of vibration are too high for civil engineering structures.

\section{Design Guidelines and Assessment Methods}

As previously mentioned, the inherent complexities of modelling HSI have caused the design guidelines to either ignore the HSI [98] or make very simplistic assumptions to take it into account. Therefore, all commonly used current design guidelines only suggest a walking GRF to be applied on the structure.

Živanović et al. [4] carried out a comprehensive study of the performance of the currently available design guidelines to estimate the response of a structure under spatially unrestricted pedestrian traffic walking loads. They analysed four time-domain methods, Eurocode 5 [99], ISO 10137 standard [100], design guidelines presented by the French road authorities [92], and UK National Annex to Eurocode 1 [101], and three frequency-domain methods, the power spectral density method proposed by Brownjohn [6], Butz $[102,103]$, and the response spectrum method formulated by Georgakis and Ingólfsson [104]. The selected methods were used to estimate the responses measured on two real-world footbridges, the Reykjavik City Footbridge (RCF) located in the Icelandic capital and the Podgorica Bridge (PB) located in the capital of Podgorica, Montenegro.

Results of the study by Živanović et al. [4] showed that these design guidelines tend to overestimate the response of the structures, especially in the case of the Podgorica footbridge. They concluded that ignoring the HSI is possibly the cause of this overestimation. They later showed that increasing the damping of the occupied structure from $0.26 \%$ to $0.67 \%$ (which is expected due to HSI) yielded an accurate estimation of the experimental response of the Podgorica footbridge. However, they suggested no model to simulate the observed HSI.

The UK recommendations for the design of permanent grandstands [105] are leading the world in promoting a realistic way to explicitly take into account the interaction of people with grandstand structures in the vertical direction. This guideline, based on the model proposed by Dougill et al. [106], uses a combination of two single-degree-offreedom (SDOF) models to simulate the aggregated effect of passive (mostly sitting) and active (mostly bouncing) people (Figure 16). Although this model aggregated the effects of people and did not take into account the inter- and intrasubject variability of people, its performance was proven much more accurate than the methods that ignore HSI $[107,108]$.

\section{Conclusions}

The reliable simulation of the interaction of a multipedestrian walking traffic with vibrating structures, such as footbridges 

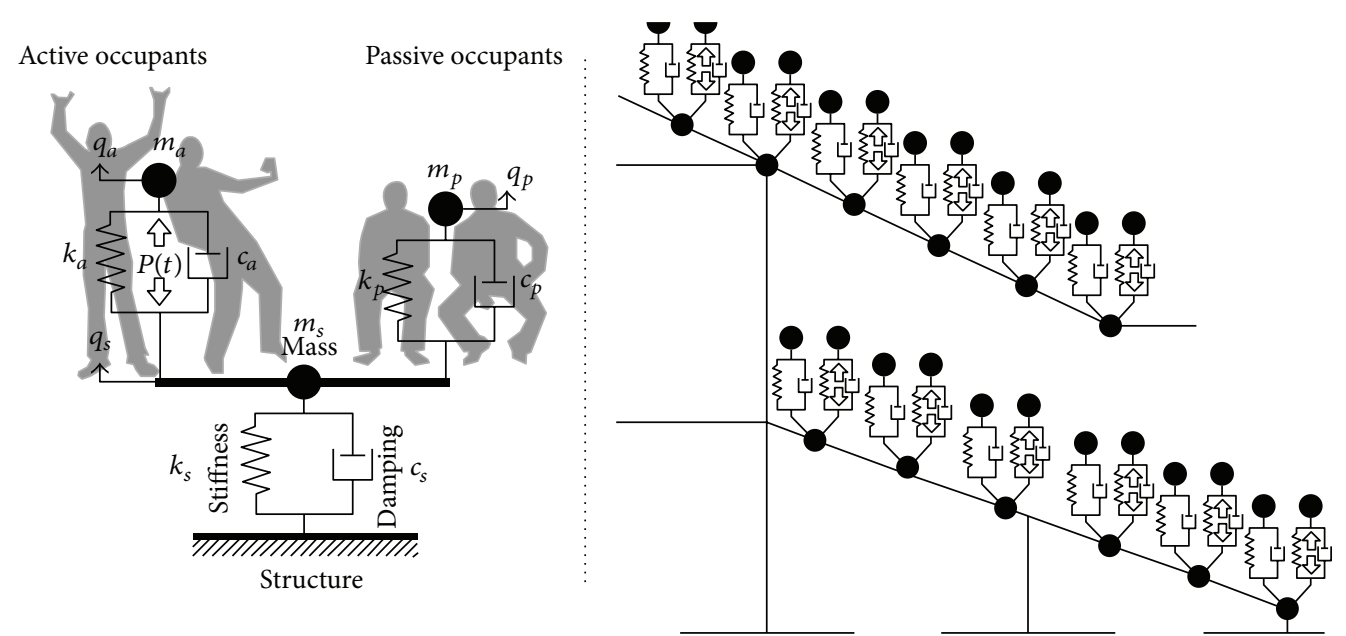

FIGURE 16: The crowd model used by UK recommendations for design of permanent grandstands [59].

and floors, is still challenging. The majority of the experimental observations and analytical studies reported in the literature suggest that

(i) walking people in general add considerably to the damping of the structure and slightly change the modal frequencies,

(ii) when the natural frequency of the walking human model $f_{h}$ is less than that of the empty structure $f_{s}$, the natural frequency of the occupied structure $f_{\text {os }}$ is expected to be higher than $f_{s}$,

(iii) when $f_{h}$ is greater than $f_{s}, f_{\text {os }}$ is expected to be less than $f_{s}$,

(iv) the closer the natural frequencies of the human to the empty structure, the greater the change in $f_{\text {os }}$ and $\zeta_{\text {os }}$,

(v) the effect of walking traffic on the modal parameters of the occupied structure becomes more significant as the number of pedestrians increases,

(vi) although identification of the dynamic properties of the walking human model has not been studied extensively in the context of vibration serviceability, the limited existing knowledge suggests ranges of $1.85-3.5 \mathrm{~Hz}$ and $20-50 \%$ for an SDOF MSD model of a walking human,

(vii) there is still no conclusive evidence on the most realistic and computationally efficient form of the walking human model (SDOF, MDOF, IP, etc.) to simulate HSI,

(viii) the existing walking human models mostly lack conclusive experimental validation and, in the case of IP models, their time-varying nonlinear interaction mechanisms are not straightforward enough to implement in practice. IP models are prone to produce results that contradict experimental observations.

Currently, no design guideline takes into account the HSI of walking pedestrians in the vertical direction. As a result, a large and potentially expensive overestimation can be expected between simulated and experimentally measured responses. There is an urgent need for a detailed and extensive experimental and analytical research on the underlying mechanisms of the HSI during walking. The resulting methodologies can then be adopted in the new generation of vibration serviceability guidelines, having to feature the effects of human-structure dynamic interaction, currently neglected for pedestrian structures but utilised for the first time and with great success since 2008 in the UK guidance on crowd dynamic loading of grandstands.

Future research in this area is needed based on collecting comprehensive interaction data from real-world structures for different walking traffic scenarios. Such datasets are necessary for varying structures to identify and validate walking human models and analyse their robustness and versatility. The next generation of design guidelines need to incorporate a realistic model of walking GRF and a comprehensive HSI model into a practical and inclusive modelling approach that can be used in day-to-day design practice. Such a modelling approach must be able to simulate the essential aspects of HSI effects such as the vertical lock-in and changes in modal parameters of the vibrating structure and human walking models.

\section{Competing Interests}

The authors declare that there are no competing interests regarding the publication of this paper.

\section{Acknowledgments}

The authors acknowledge the financial support which came from the University of Sheffield doctoral scholarship for Dr. Shahabpoor and the UK Engineering and Physical Sciences Research Council (EPSRC) for the following research grants: (i) Platform Grant EP/G061130/2 (Dynamic Performance of Large Civil Engineering Structures: An Integrated Approach to Management, Design and Assessment), (ii) Standard 
Grant EP/I029567/1 (Synchronisation in Dynamic Loading due to Multiple Pedestrians and Occupants of VibrationSensitive Structures), and (iii) Frontier Engineering Grant EP/K03877X/1 (Modelling Complex and Partially Identified Engineering Problems: Application to the Individualised Multiscale Simulation of the Musculoskeletal System).

\section{References}

[1] A. Fitzpatrick, P. Dallard, S. le Bourva, A. Low, R. Ridsill Smith, and M. Willford, Linking London: The Millennium Bridge, The Royal Academy of Engineering, London, UK, 2001.

[2] M. Willford, "Dynamic actions and reactions of pedestrians," in Proceedings of the International Conference on the Design and Dynamic Behaviour of Footbridges, pp. 66-73, Paris, France, 2002.

[3] R. L. Pimentel, A. Pavic, and P. Waldron, "Evaluation of design requirements for footbridges excited by vertical forces from walking," Canadian Journal of Civil Engineering, vol. 28, no. 5, pp. 769-777, 2001.

[4] S. Živanović, A. Pavić, and E. T. Ingólfsson, "Modeling spatially unrestricted pedestrian traffic on footbridges," Journal of Structural Engineering, vol. 136, no. 10, pp. 1296-1308, 2010.

[5] J. M. W. Brownjohn, "Vibration serviceability of footbridges," in Proceedings of the 2nd International Conference on Structural Engineering, Mechanics and Computation, pp. 419-423, 2004.

[6] J. M. W. Brownjohn, A. Pavic, and P. A. Omenzetter, "A spectral density approach for modelling continuous vertical forces on pedestrian structures due to walking," Canadian Journal of Civil Engineering, vol. 31, no. 1, pp. 65-77, 2004.

[7] M. Kasperski and C. Sahnaci, "Serviceability of pedestrian structures," in Proceedings of the 25th Conference and Exposition on Structural Dynamics 2007, pp. 774-798, Orlando, Fla, USA, February 2007.

[8] E. Shahabpoor and A. Pavic, "Comparative evaluation of current pedestrian traffic models on structures," in Topics on the Dynamics of Civil Structures, Volume 1: Proceedings of the 30th IMAC, A Conference on Structural Dynamics, 2012, Conference Proceedings of the Society for Experimental Mechanics Series, pp. 41-52, Springer, Berlin, Germany, 2012.

[9] F. Ricciardelli and C. Demartino, "Design of footbridges against pedestrian-induced vibrations," ASCE Journal of Bridge Engineering, 2016.

[10] B. R. Ellis and T. Ji, "Human-structure interaction in vertical vibrations," Proceedings of the Institution of Civil EngineersStructures and Buildings, vol. 122, no. 1, pp. 1-9, 1997.

[11] S. Živanović, I. M. Diaz, and A. Pavic, "Influence of walking and standing crowds on structural dynamic properties," in Proceedings of the 27th Conference \& Exposition on Structural Dynamics (IMAC '09), Orlando, Fla, USA, February 2009.

[12] V. Racic and J. M. W. Brownjohn, "Stochastic model of nearperiodic vertical loads due to humans walking," Advanced Engineering Informatics, vol. 25, no. 2, pp. 259-275, 2011.

[13] S. Živanović, A. Pavić, and P. Reynolds, "Probability-based prediction of multi-mode vibration response to walking excitation," Engineering Structures, vol. 29, no. 6, pp. 942-954, 2007.

[14] S. Živanović and A. Pavić, "Probabilistic modeling of walking excitation for building floors," Journal of Performance of Constructed Facilities, vol. 23, no. 3, pp. 132-143, 2009.
[15] G. Piccardo and F. Tubino, "Equivalent spectral model and maximum dynamic response for the serviceability analysis of footbridges," Engineering Structures, vol. 40, pp. 445-456, 2012.

[16] S. Krenk, "Dynamic response to pedestrian loads with statistical frequency distribution," Journal of Engineering Mechanics, vol. 138, no. 10, pp. 1275-1281, 2012.

[17] C. C. Caprani, "Application of the pseudo-excitation method to assessment of walking variability on footbridge vibration," Computers and Structures, vol. 132, pp. 43-54, 2014.

[18] S. Živanović, A. Pavic, and P. Reynolds, "Vibration serviceability of footbridges under human-induced excitation: a literature review," Journal of Sound and Vibration, vol. 279, no. 1-2, pp. 174, 2005.

[19] R. Sachse, The influence of human occupants on the dynamic properties of slender structures [Ph.D. thesis], University of Sheffield, Sheffield, UK, 2003.

[20] A. Ebrahimpour and R. L. Sack, "Design live loads for coherent crowd harmonic movements," Journal of Structural Engineering, vol. 118, no. 4, pp. 1121-1136, 1992.

[21] M. Kasperski and H. J. Niemann, "Man induced vibrations of a stand structure," in Proceedings of the 2nd European Conference on Structural Dynamics (EURODYN '93), pp. 977983, Trondheim, Norway, June 1993.

[22] Y. Fujino, B. M. Pacheco, S.-I. Nakamura, and P. Warnitchai, "Synchronization of human walking observed during lateral vibration of a congested pedestrian bridge," Earthquake Engineering and Structural Dynamics, vol. 22, no. 9, pp. 741-758, 1993.

[23] P. Van Staalduinen and W. Courage, "Dynamic loading of Feyenoord stadium during pop concerts," in Symposium: Places of Assembly and Long-Span Building Structures, Birmingham, UK, 7-9 September, 1994, Report 71, pp. 283-288, IABSE, Zürich, Switzerland, 1994.

[24] M. J. Griffin, Handbook of Human Vibration, Academic Press, London, UK, 1990.

[25] V. Racic, J. M. W. Brownjohn, and A. Pavic, "Reproduction and application of human bouncing and jumping forces from visual marker data," Journal of Sound and Vibration, vol. 329, no. 16, pp. 3397-3416, 2010.

[26] R. Sachse, A. Pavic, and P. Reynolds, "The influence of a group of human occupants on modal properties of a prototype assembly structure," in Proceeding of the 5th European Conference on Dynamics (EURODYN '02), pp. 1241-1246, Munich, Germany, September 2002.

[27] R. Sachse, A. Pavic, and P. Reynolds, "Human-structure dynamic interaction in civil engineering dynamics: a literature review," The Shock and Vibration Digest, vol. 35, no. 1, pp. 3-18, 2003.

[28] C. Butz, M. Feldmann, and C. Heinemeyer, "Advanced load models for synchronous pedestrian excitation and optimized design guidelines for steel footbridges," Tech. Rep. RFSRCT2003-00019, European Commission, Brussels, Belgium, 2008.

[29] P. Reynolds, A. Pavic, and Z. Ibrahim, "Changes of modal properties of a stadium structure occupied by a crowd," in Proceedings of the 22nd International Modal Analysis Conference (IMAC-XXII '04), Dearborn, Mich, USA, January 2004.

[30] K. A. Salyards and R. Firman, "Human-structure interaction effects of crowd characteristics," in Proceedings of the 29th IMAC of the Society for Experimental Mechanics Series, Civil Engineering Topics, vol. 4, pp. 247-254, Springer, 2011.

[31] C. Barker and D. Mackenzie, "Calibration of the UK national annex," in Proceedings of the 3rd Footbridge International Conference, Porto, Portugal, 2008. 
[32] C. T. Georgakis and N. G. Jorgensen, "Change in mass and damping on vertically vibrating footbridges due to pedestrians," in Proceedings of the 31st Conference on Structural Dynamics (IMAC '13), vol. 3, pp. 37-45, 2013.

[33] S. Ohlsson, Floor vibrations and human discomfort [Ph.D. thesis], Chalmers University of Technology, Gothenburg, Sweden, 1982.

[34] K. Baumann and H. Bachmann, "Durch menschen verursachte dynamische lasten und deren auswirkungen auf balkentragwerke," Report 7501-3, Institute of Structural Engineering (IBK), Swiss Federal Institute of Technology (ETH), Zürich, Switzerland, 1988.

[35] R. L. Pimentel, Vibration performance of pedestrian bridges due to human-induced loads [Ph.D. thesis], University of Sheffield, Sheffield, UK, 1997.

[36] R. L. Ebrahimpour, P. D. Sack, and Van Cleek, "Computing crowd loads using a nonlinear equation of motion," in Proceedings of the 4th International Conference on Civil and Structural Engineering Computing, pp. 47-52, Civil-Comp Press, Edinburgh, UK, 1989.

[37] A. Ebrahimpour and R. L. Sack, "Design live loads for crowds in motion," in Conference Proceeding of Building an International Community of Structural Engineers, vol. 1, pp. 420-427, ASCE, 1996.

[38] N. W. M. Bishop, M. Willford, and R. Pumphrey, Multi-Person Excitation of Modern Slender Staircases, Engineering for Crowd Safety, London, UK, 1993.

[39] R. L. Pimentel and P. Waldron, "Validation of the numerical analysis of a pedestrian bridge for vibration serviceability applications," in Proceedings of the International Conference on Identification in Engineering Systems, pp. 648-657, Swansea, UK, 1996.

[40] J. M. W. Brownjohn, P. Fok, M. Roche, and P. Omenzetter, "Long span steel pedestrian bridge at Singapore Changi Airportpart 2: crowd loading tests and vibration mitigation measures," Structural Engineer, vol. 82, no. 16, pp. 28-34, 2004.

[41] J. M. W. Brownjohn and T. N. Fu, "Vibration excitation and control of a pedestrian walkway by individuals and crowds," Shock and Vibration, vol. 12, no. 5, pp. 333-347, 2005.

[42] P. J. Fanning, P. Healy, and A. Pavic, "Pedestrian bridge vibration serviceability: a case study in testing and simulation," Advances in Structural Engineering, vol. 13, no. 5, pp. 861-873, 2010.

[43] W. Dong, M. Kasperski, and G. Shiqiao, "Change of dynamic characteristics of a pedestrian bridge during a mass event," in Proceedings of the 8th International Conference on Structural Dynamics (EURODYN '11), Leuven, Belgium, July 2011.

[44] M. Zhang, C. T. Georgakis, W. Qu, and J. Chen, "SMD model parameters of pedestrians for vertical human-structure interaction," in Proceedings of the 33rd Conference and Exposition on Balancing Simulation and Testing (IMAC '15), pp. 311-317, February 2015.

[45] K. Van Nimmen, K. Maes, S. Živanović, G. Lombaert, G. De Roeck, and P. Van den Broeck, "Identification and modelling of vertical human-structure interaction," in Proceedings of the 33rd Conference and Exposition on Balancing Simulation and Testing (IMAC '15), pp. 319-330, February 2015.

[46] K. A. Salyards and Y. Hua, "Assessment of dynamic properties of a crowd model for human-structure interaction modeling," Engineering Structures, vol. 89, pp. 103-110, 2015.

[47] C. C. Caprani, J. Keogh, P. Archbold, and P. Fanning, "Characteristic vertical response of a footbridge due to crowd loading," in Proceeding of the 8th International Conference on Structural Dynamics (Eurodyn '11), pp. 978-985, Leuven, Belgium, 2011.

[48] F. T. Silva, H. M. B. F. Brito, and R. L. Pimentel, "Modeling of crowd load in vertical direction using biodynamic model for pedestrians crossing footbridges," Canadian Journal of Civil Engineering, vol. 40, no. 12, pp. 1196-1204, 2013.

[49] International Organization for Standardization (ISO), "Mechanical driving point impedance of the human body," ISO 5982:1981, 1981.

[50] E. Shahabpoor, A. Pavic, and V. Racic, "Identification of massspring-damper model of walking humans," in Proceedings of the Structures Congress, pp. 912-923, Portland, Ore, USA, April 2015.

[51] E. Shahabpoor, A. Pavic, and V. Racic, "Identification of massspringdamper model of walking humans," Structures, vol. 5, pp. 233-246, 2016.

[52] E. Shahabpoor, A. Pavic, and V. Racic, "Using MSD model to simulate human-structure interaction during walking," in Proceedings of the 31st IMAC, A Conference on Structural Dynamics, vol. 4 of Conference Proceedings of the Society for Experimental Mechanics Series, pp. 357-364, Springer, 2013.

[53] M. Bocian, J. Macdonald, and J. Burn, "Modelling of self-excited vertical forces on structures due to walking pedestrians," in Proceedings of the 8th International Conference on Structural Dynamics (EURODYN '11), Leuven, Belgium, July 2011.

[54] J. W. Qin, S. S. Law, Q. S. Yang, and N. Yang, "Pedestrian-bridge dynamic interaction, including human participation," Journal of Sound and Vibration, vol. 332, no. 4, pp. 1107-1124, 2013.

[55] J. W. Qin, S. S. Law, Q. S. Yang, and N. Yang, "Finite element analysis of pedestrian-bridge dynamic interaction," Journal of Applied Mechanics, vol. 81, no. 4, Article ID 041001, 2014.

[56] J. Maca and M. Valasek, "Interaction of human gait and footbridges," in Proceedings of the 8th International Conference on Structural Dynamics (EURODYN '11), Leuven, Belgium, 2011.

[57] H. Grundmann, H. Kreuzinger, and M. Schneider, "Dynamic calculations of footbridges," Bauingenieur, vol. 68, pp. 215-225, 1993 (German).

[58] S. Živanović, Probability-based estimation of vibration for pedestrian structures due to walking [Ph.D. thesis], Department of Civil and Structural Engineering, University of Sheffield, Sheffield, UK, 2006.

[59] C. A. Jones, P. Reynolds, and A. Pavic, "Vibration serviceability of stadia structures subjected to dynamic crowd loads: a literature review," Journal of Sound and Vibration, vol. 330, no. 8, pp. 1531-1566, 2011.

[60] P. J. Archbold, Interactive load models for pedestrian footbridges [Ph.D. thesis], National University of Ireland, University College Dublin, 2004.

[61] P. J. Fanning, P. Archbold, and A. Pavic, "A novel interactive pedestrian load model for flexible footbridges," in Proceedings of the SEM Annual Conference and Exposition on Experimental and Applied Mechanics, pp. 573-580, Portland, Ore, USA, June 2005.

[62] P. J. Archbold, J. Keogh, C. Caprani, and P. Fanning, "A parametric study of pedestrian vertical force models for dynamic analysis of footbridges," in Proceeding of the Experimental Vibration Analysis for Civil Engineering Structures Conference (EVACES '11), 2011.

[63] F. T. Silva and R. L. Pimentel, "Biodynamic walking model for vibration serviceability of footbridges in vertical direction," in Proceeding of the 8th International Conference on Structural Dynamics (Eurodyn '11), pp. 1090-1096, Leuven, Belgium, 2011. 
[64] E. Shahabpoor, A. Pavic, and V. Racic, "Sensitivity analysis of coupled crowd-structure system dynamics to walking crowd properties," in Proceedings of the 5th International Conference on Structural Engineering, Mechanics and Computation (SEMC '13), pp. 143-148, September 2013.

[65] J. F. Jiménez Alonso and A. Sáez, "A direct pedestrian structure interaction model to characterize the human induced vibrations on slender footbridges," Informes de la Construcción, vol. 66, no. 1, article m007, 2014.

[66] M. A. Toso, H. M. Gomes, F. T. Silva, and R. L. Pimentel, "Experimentally fitted biodynamic models for pedestrian-structure interaction in walking situations," Mechanical Systems and Signal Processing, vol. 72-73, pp. 590-606, 2016.

[67] S. H. Kim, K. I. Cho, M. S. Choi, and J. Y. Lim, "Development of human body model for the dynamic analysis of footbridges under pedestrian induced excitation," International Journal of Steel Structures, vol. 8, no. 4, pp. 333-345, 2008.

[68] M. Bocian, J. H. Macdonald, and J. F. Burn, "Biomechanically inspired modeling of pedestrian-induced vertical self-excited forces," Journal of Bridge Engineering, vol. 18, no. 12, pp. 13361346, 2013.

[69] H. V. Dang and S. Živanović, "Modelling pedestrian interaction with perceptibly vibrating footbridges," FME Transactions, vol. 41, no. 4, pp. 271-278, 2013.

[70] T. Ji, "On the combination of structural dynamics and biodynamics methods in the study of human-structure interaction," in Proceedings of the 35th United Kingdom Group Meeting on Human Response to Vibration, vol. 1, pp. 183-194, Institute of Sound and Vibration Research, University of Southampton, Southampton, England, September 2000.

[71] F. Walley, "St James's Park bridge," Proceedings of the Institution of Civil Engineers, vol. 12, no. 2, pp. 217-222, 1959.

[72] D. E. Allen and J. H. Rainer, Floor Vibration, NRCC, Canadian Building Digest (CBD), Ottawa, Canada, 1975.

[73] K. Portier, J. K. Tolson, and S. M. Roberts, "Body weight distributions for risk assessment," Risk Analysis, vol. 27, no. 1, pp. 11-26, 2007.

[74] A. M. F. Barela and M. Duarte, "Biomechanical characteristics of elderly individuals walking on land and in water," Journal of Electromyography and Kinesiology, vol. 18, no. 3, pp. 446-454, 2008.

[75] Y. Matsumoto, T. Nishioka, H. Shiojiri, and K. Matsuzaki, Dynamic Design of Footbridges, vol. 2 of IABSE Proceedings, Paper P-17/78, IABSE, Zurich, Switzerland, 1978.

[76] H. Grundmann and M. Schneider, "Stochastic representation of footbridge vibrations taking into account feedback effects," in Proceeding of European Conference on Structural Engineering (Eurodyn '90), Bochum, Germany, 1990.

[77] A. Pachi and T. Ji, "Frequency and velocity of people walking," The Structural Engineer, vol. 83, no. 3, pp. 36-40, 2005.

[78] A. Ebrahimpour, A. Hamam, R. L. Sack, and W. N. Patten, "Measuring and modeling dynamic loads imposed by moving crowds," Journal of Structural Engineering, vol. 122, no. 12, pp. 1468-1474, 1996.

[79] C. R. Lee and C. T. Farley, "Determinants of the center of mass trajectory in human walking and running," The Journal of Experimental Biology, vol. 201, no. 21, pp. 2935-2944, 1998.

[80] S. Živanović, "Modelling human actions on lightweight structures: experimental and numerical developments," MATEC Web of Conferences, vol. 24, Article ID 01005, 2015.
[81] D. Zhou, H. Han, T. Ji, and X. Xu, "Comparison of two models for human-structure interaction," Applied Mathematical Modelling, vol. 40, no. 5-6, pp. 3738-3748, 2016.

[82] Y. Miyamori, T. Obata, T. Hayashikawa, and K. Sato, "Study on identification of human walking model based on dynamic response characteristics of pedestrian bridges," in Proceedings of the 8th East Asia-Pacific Conference on Structural Engineering \& Construction (EASEC-8), Singapore, 2001.

[83] H. V. Dang, Experimental and numerical modelling of walking locomotion on vertically vibrating low-frequency structures [Ph.D. thesis], University of Warwick, England, UK, 2014.

[84] S. A. Gard and D. S. Childress, "What determines the vertical displacement of the body during normal walking?" Journal of Prosthetics and Orthotics, vol. 13, no. 3, pp. 64-67, 2001.

[85] H. Geyer, Simple models of legged locomotion based on compliant limb behaviour [Ph.D. thesis], Friedrich-Schiller-Universität Jena, Jena, Germany, 2005.

[86] S. Kim and S. Park, "Leg stiffness increases with speed to modulate gait frequency and propulsion energy," Journal of Biomechanics, vol. 44, no. 7, pp. 1253-1258, 2011.

[87] J. B. Saunders, V. T. Inman, and H. D. Eberhart, "The major determinants in normal and pathological gait," The Journal of Bone \& Joint Surgery - American Volume, vol. 35, no. 3, pp. 543558, 1953.

[88] B. R. Whittington and D. G. Thelen, "A simple mass-spring model with roller feet can induce the ground reactions observed in human walking," Journal of Biomechanical Engineering, vol. 131, no. 1, Article ID 011013, 2009.

[89] D. R. Humphrey and J. R. Dawin, "Separate cortical systems for control of joint movement and joint stiffness: reciprocal activation and co-activation of antagonist muscles," Motor Control Mechanisms in Health and Diseases, vol. 39, pp. 347-372, 1983.

[90] A. McRobie, G. Morgenthal, J. Lasenby, and M. Ringer, "Section model tests on human structure lock- in," Proceedings of the Institution of Civil Engineers-Bridge Engineering, vol. 156, no. 2, pp. 71-79, 2003.

[91] H. Bachmann and W. Ammann, Vibrations in Structures Induced by Man and Machines, International Association for Bridge and Structural Engineering (IABSE), Zurich, Switzerland, 1987.

[92] Technical Department for Transport, Roads and Bridges Engineering, and Road Safety/French Association of Civil Engineering (SETRA/AFGC), "Footbridges: assessment of vibrational behaviour of footbridges under pedestrian loading," Technical Guide 0611, SETRA/AFGC, Paris, France, 2006.

[93] S. Živanović, A. Pavic, and P. Reynolds, "Human-structure dynamic interaction in footbridges," Proceedings of the Institution of Civil Engineers: Bridge Engineering, vol. 158, no. 4, pp. 165-177, 2005.

[94] M. Feldmann, Ch. Heinemeyer, M. Lukic et al., Human-Induced Vibration of Steel Structures (Hivoss), Research Fund for Coal and Steel, European Commission, 2008.

[95] B. Hinz and H. Seidel, "The non-linearity of the human body's dynamic response during sinusoidal whole body vibration," Industrial Health, vol. 25, no. 4, pp. 169-181, 1987.

[96] Y. Matsumoto and M. J. Griffin, "Dynamic response of the standing human body exposed to vertical vibration: influence of posture and vibration magnitude," Journal of Sound and Vibration, vol. 212, no. 1, pp. 85-107, 1998. 
[97] N. J. Mansfield and M. J. Griffin, "Non-linearities in apparent mass and transmissibility during exposure to whole-body vertical vibration," Journal of Biomechanics, vol. 33, no. 8, pp. 933941, 2000.

[98] T. M. Murray, D. E. Allen, and E. E. Ungar, Floor Vibrations due to Human Activity, Steel Design Guide Series, American Institute of Steel Construction, Chicago, Ill, USA, 2003.

[99] EN, "Eurocode 5: design of timber structures-part 2: bridges," EN 1995-2:2004, European Committee of Standardization, 2004.

[100] International Organization for Standardization (ISO), "Bases for design of structures: serviceability of buildings and walkways against vibrations," ISO 10137:2007, International Organization for Standardization (ISO), Geneva, Switzerland, 2007.

[101] British Standards Institution (BSI), UK national annex to Eurocode 1: Actions on structures. Part 2: Traffic loads on bridges, NA to BS EN 1991-2:2003 London, 2008.

[102] C. Butz, Beitrag zur berechnung fußgangerinduzierte bruckenschwingungen [Ph.D. thesis], Shaker Verlag Aachen, 2006 (German).

[103] C. Butz, "A probabilistic engineering load model for pedestrian streams," in Proceedings of the 3rd International Footbridge Conference, Porto, Portugal, 2008.

[104] C. T. Georgakis and E. T. Ingólfsson, "Vertical footbridge vibrations: the response spectrum methodology," in Proceedings of the 3rd International Footbridge Conference, Porto, Portugal, 2008.

[105] IStructE/DCLG/DCMS Joint Working Group, Dynamic Performance Requirements for Permanent Grandstands Subject to Crowd Action: Recommendations for Management, Design and Assessment, Institution of Structural Engineers (IStructE), London, UK, 2008.

[106] J. W. Dougill, J. R. Wright, J. G. Parkhouse, and R. E. Harrison, "Human structure interaction during rhythmic bobbing," The Structural Engineer, vol. 118, no. 4, pp. 32-39, 2006.

[107] A. Pavic and P. Reynolds, "Experimental verification of novel 3DOF model for grandstand crowd-structure dynamic interaction," in Proceeding of the 26th International Modal Analysis Conference (IMAC '08), 2008.

[108] C. A. Jones, A. Pavic, P. Reynolds, and R. E. Harrison, "Verification of equivalent mass-spring-damper models for crowdstructure vibration response prediction," Canadian Journal of Civil Engineering, vol. 38, no. 10, pp. 1122-1135, 2011. 


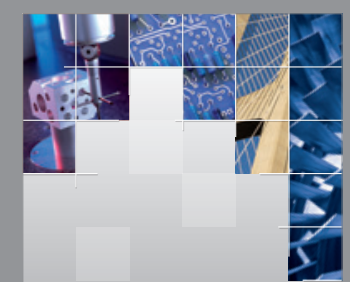

\section{Enfincering}
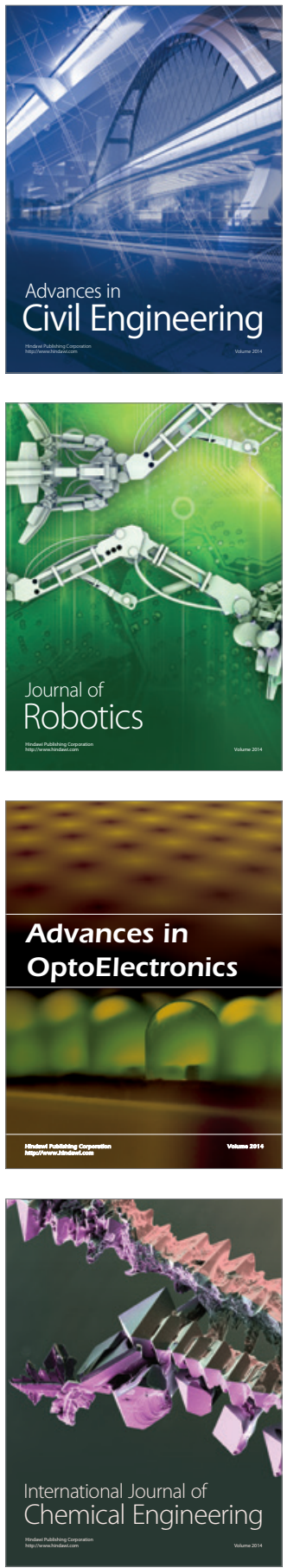

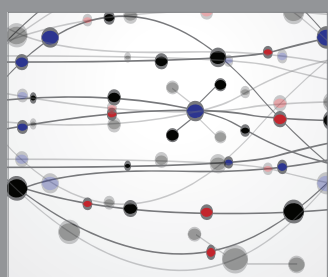

The Scientific World Journal

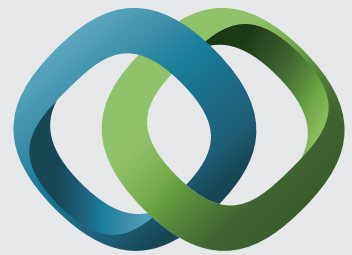

\section{Hindawi}

Submit your manuscripts at

http://www.hindawi.com
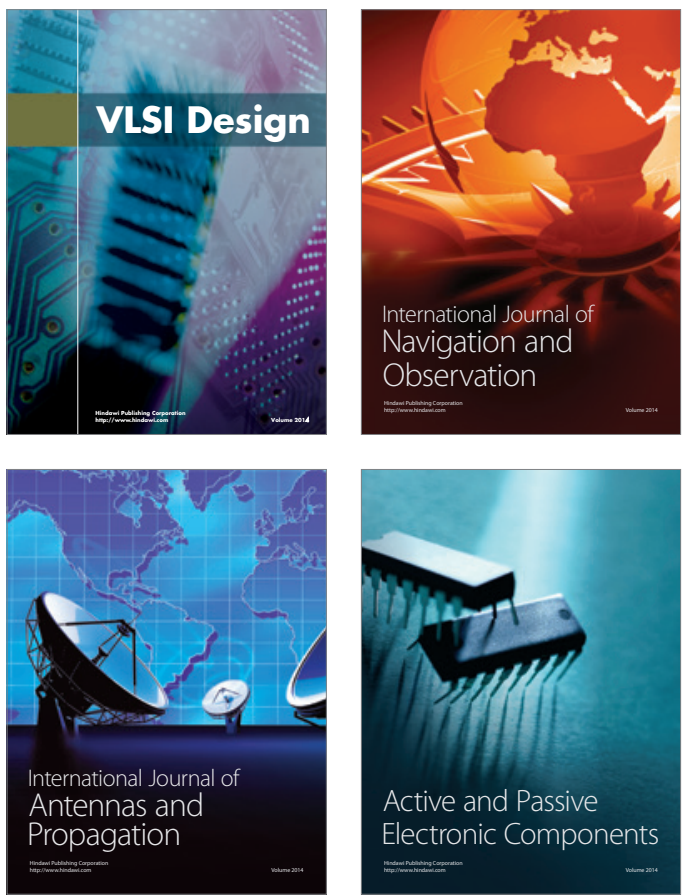
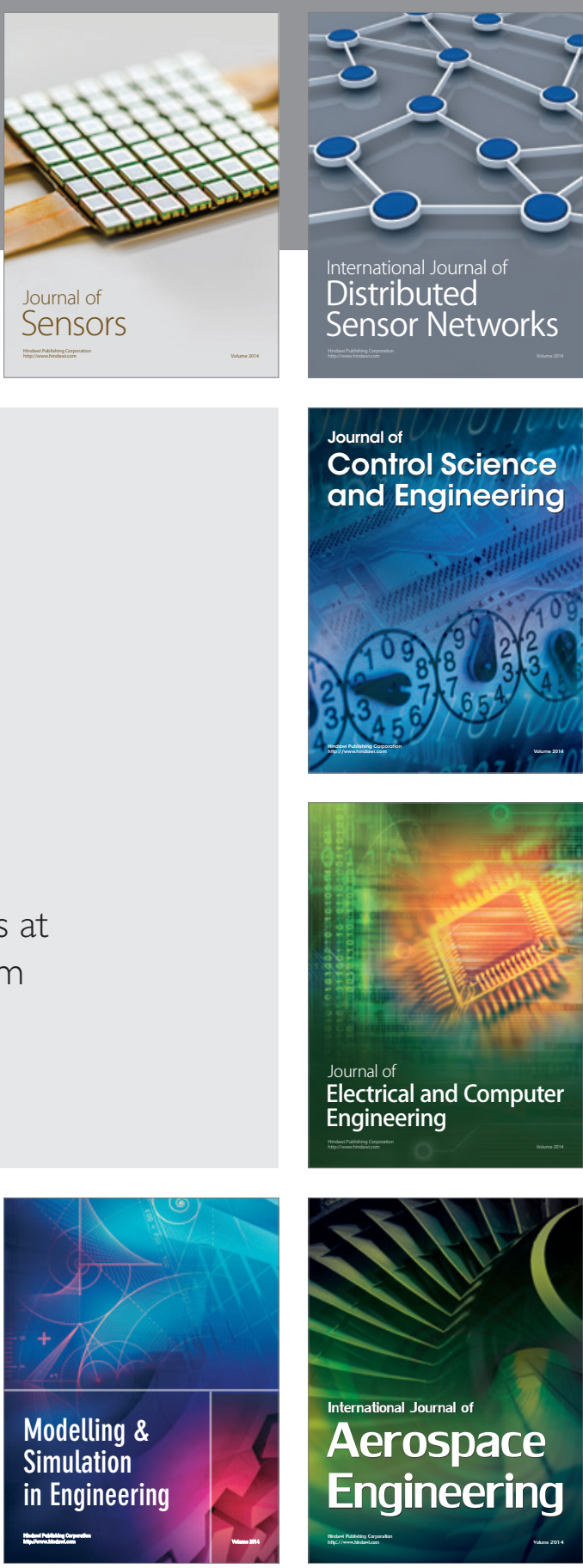

International Journal of

Distributed

Sensor Networks

Journal of

Control Science

and Engineering
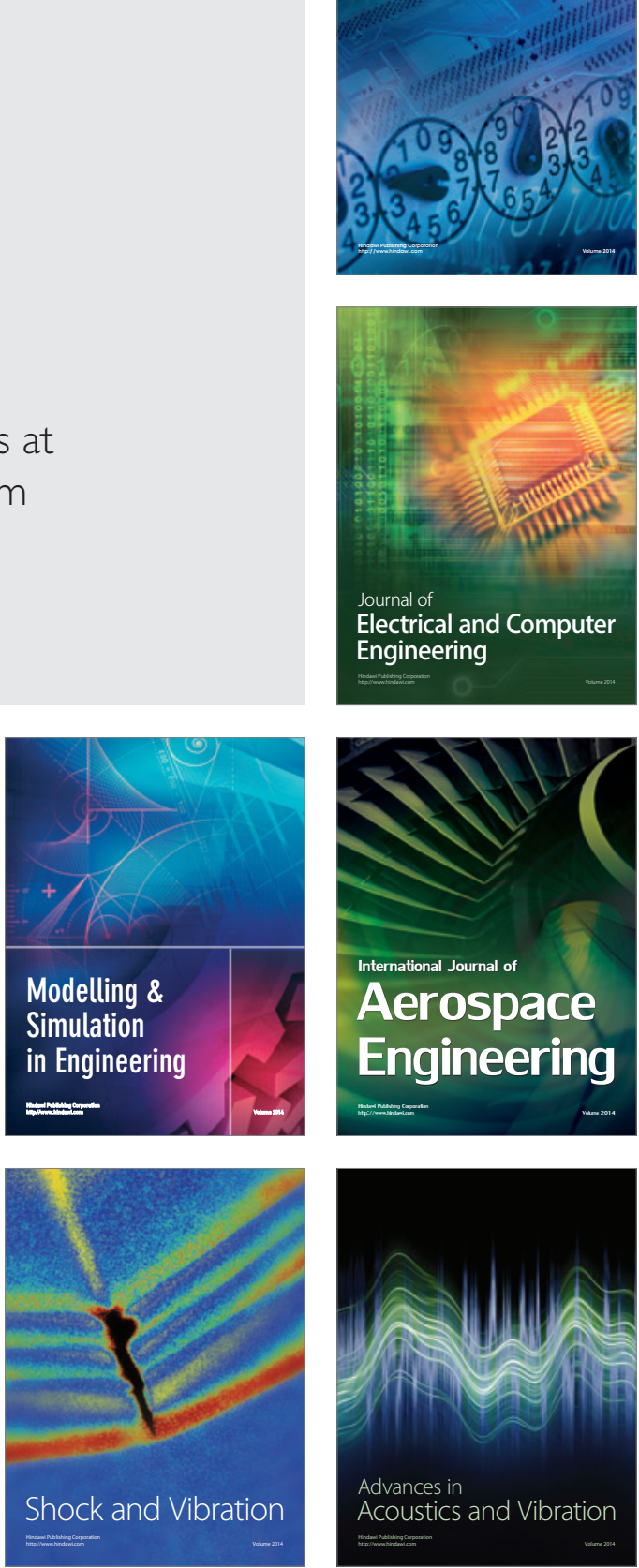